\title{
Detection of Chaetomium globosum, Ch. cochliodes and $C h$. rectangulare during the Diversity Tracking of Mycotoxin-Producing Chaetomium-like Isolates Obtained in Buildings in Finland
}

\author{
Johanna M. Salo ${ }^{1, *,+}$, Orsolya Kedves ${ }^{2,+}$, Raimo Mikkola ${ }^{1}$ (D) László Kredics ${ }^{2}$, \\ Maria A. Andersson ${ }^{1}$, Jarek Kurnitski ${ }^{1,3}\left(\mathbb{D}\right.$ and Heidi Salonen ${ }^{1}$ \\ 1 Department of Civil Engineering, Aalto University, Box 12100, FI-00076 Aalto, Finland; \\ raimo.mikkola@aalto.fi (R.M.); aino.andersson@aalto.fi (M.A.A.); jarek.kurnitski@aalto.fi (J.K.); \\ heidi.salonen@aalto.fi (H.S.) \\ 2 Department of Microbiology, Faculty of Science and Informatics, University of Szeged, Közép fasor 52, \\ 6726 Szeged, Hungary; varga_orsi91@yahoo.com (O.K.); kredics@bio.u-szeged.hu (L.K.) \\ 3 Department of Civil Engineering and Architecture, Tallinn University of Technology, Ehitajate tee 5, \\ 19086 Tallinn, Estonia \\ * Correspondence: johanna.72salo@gmail.com; Tel.: +358-50-3601-468 \\ + Equal contribution.
}

Received: 14 June 2020; Accepted: 6 July 2020; Published: 8 July 2020

\begin{abstract}
The diversity of Chaetomium-like isolates in buildings in Finland is poorly documented. This paper describes a set of methods for rapid diversity tracking of 42 indoor Chaetomium-like isolates. These isolates were categorized based on their fluorescence emission, ascomatal hair morphology, responses in three bioassays and resistance/sensitivity to the wetting agent Genapol X-080. Thirty-nine toxigenic isolates were identified [Ch. globosum $(n=35)$, Ch. cochliodes $(n=2)$ and Ch. rectangulare $(n=2)]$. These isolates were identified down to the species level by tef1 $\alpha$ gene sequencing. The major toxic substances in the ethanol extracts of the Ch. globosum and Ch. cochliodes strains were chaetoglobosin, chaetoviridin A and C, chaetomugilin D and chaetomin, identified based on HPLC-UV and mass spectrometry data (MS and MS/MS). Ethanol extracts from pure Ch. globosum cultures exhibited a toxicological profile in the boar sperm motility inhibition assay (BSMI), sperm membrane integrity damage assay (SMID) and inhibition of cell proliferation (ICP) assay, similar to that exhibited by pure chaetoglobosin A. Overall, differences in fluorescence, morphology, toxicity profile, mycotoxin production and sensitivity to chemicals were consistent with those in tef $1 \alpha$ sequencing results for species identification. The results indicate the presence of $\mathrm{Ch}$. cochliodes and Ch. rectangulare in Finnish buildings, representing a new finding.
\end{abstract}

Keywords: Chaetomium globosum; Chaetomium cochliodes; Chaetomium rectangulare; mycotoxin; chaetoglobosin; chaetomin; chaetoviridin A and C; chaetomugilin D; indoor mold; fluorescence

Key Contribution: This study describes the methods used to detect indoor Ch. globosum and Ch. cochliodes isolates.

\section{Introduction}

The family Chaetomiaceae consists of globally ubiquitous fungal genera that are found in soil and degraded cellulosic materials, such as dung and wastes. This family comprises mesophilic, thermotolerant and thermophilic genera which demonstrate mycelial growth at $15-55^{\circ} \mathrm{C}$. The genera belonging to Chaetomiaceae are characterized by ascomata containing ascospores in deliquescent asci 
found inside the ornamented perithecia [1-3]. Indoor isolates producing dark pigmented hairy ascomata are usually assigned to the genus Chaetomium and are often tentatively recognized at the species level as Chaetomium globosum or Chaetomium spp., which has been reported as a dominant fungal species in damp and water-damaged building materials in Denmark and Greenland $[4,5]$.

A member of Chaetomiaceae, Ch. globosum is the most common if not the only member of this family to be found in indoor environments in Finland [6-8]. It is also the only species and a member of the only genus in Chaetomiaceae to be listed in the Finnish Environmental Relative Moldiness Index (FERMI). This simplified metric based on 10 mold species and the inclusion of these 10 species into the FERMI were explained by Täubel et al. [8]. However, not all dark ascomata-producing isolates found in indoor environments are Ch. globosum, and they are not necessarily members of the genus Chaetomium. A study involving 145 indoor Chaetomiaceae isolates identified in 19 countries reported that 30 species found in indoor environments could be accommodated in 10 genera of Chaetomiaceae [2]. The most common indoor isolates worldwide belong to the genus Chaetomium, and they were assigned to the Ch. globosum complex and to Ch. globosum, Ch. cochliodes and Ch. elatus (closely related to Ch. rectangulare); collectively, they represent $70 \%$ of the 145 isolates $[2,3,9]$. These studies showed that, although the members of the Ch. globosum complex were the most abundant in indoor environments, other Chaetomium-like isolates were also present. The high number of newly detected species and genera indicated that the diversity of indoor Chaetomiaceae is not well known [3].

Mycotoxins are bioactive secondary metabolites excreted by fungi. They regulate metabolic and ecological processes essential for a producer [10]. In mammalian cells, they may interfere with cellular structures (e.g., biomembranes) and with important cellular processes (e.g., protein, RNA and DNA syntheses; ion homeostasis; energy metabolism; and mitochondrial functions) [11-18]. Most mycotoxins exert immunosuppressive effects, and many of them are cytotoxic/cytostatic and thus could potentially damage the skin and lungs and could affect the gut microbiota [19-22]. In addition, they may affect the physical defense mechanisms of the respiratory tract, and this phenomenon is described as the ciliostatic effect of the metabolites produced by Chaetomium spp. Ciliostatic effects may reduce the ability of the respiratory tract to purify particulate pollutants (including bacteria or viruses) [20,23-25]. Moreover, mycotoxins could damage the macrophages of alveoli, thereby preventing the elimination of pollutants from the deeper lungs, resulting in increased susceptibility to infectious diseases and in reduced defense against other contaminants [19,23-28]. However, the health risk associated with mycotoxins in urban indoor environments remains controversial [21], and no safety limits for exposure to airborne mycotoxins or to indoor mold growth have been established.

The presence of the representants of Chaetomiaceae, especially the representants of the genus Chaetomium, in indoor environments is of concern due to the following reasons: (A) The representants of the genus Chaetomium degrade moist cellulose-containing building materials, such as timber and plywood, as well as synthetic building materials, such as plastics. In moist materials, they may evolve as the dominant fungal colonizers, forming dense mycelial growths covering large areas of building materials, thereby possibly affecting building structures [5,29]. (B) A causal relationship between exposure to actively growing indoor molds (identified based on mold odor and visible mold growth on building materials) and the development and exacerbation of asthma in children is suggested in a review of longitudinal studies [30]. The secondary metabolites of the genus Chaetomium are suspected to exert a negative impact on human health. The secondary metabolites of Ch. globosum, such as chaetoglobosins and chaetoviridins/ chaetomugilins, have been found in building materials in quantities of 950 and $200 \mathrm{mg} \mathrm{m}^{-2}$, respectively [9]. (C) Representants of the genus Chaetomium are associated with severe secondary infections in human patients and also with onychomycoses in healthy individuals [31]. In addition, members of the genus Chaetomium may have a latent clinical potential to cause invasive mold infections [32]. However, whether the species constituting the Ch. globosum complex, which cannot grow at temperatures higher than $35^{\circ} \mathrm{C}$, are causing the described infections remains controversial. The reported infections may have been caused by closely related species included in the Ch. globosum complex, such as Ch. megalosporum [3,32,33]. 
The negative impacts of Chaetomium infestation in buildings have most often been associated with Ch. globosum. Such a correlation justifies the inclusion of Ch. globosum as an indicator fungus in the FERMI; at the same time, it underlines the importance of accurate identification of the species and the acquisition of knowledge on the diversity of Chaetomium-like fungi in indoor environments in Finland. Recognition of toxic metabolite-producing Chaetomium isolates, especially the Ch. globosum isolates, is thus of concern, and methods that speed up the diversity tracking of indoor Chaetomiaceae isolates may be useful for the rapid characterization of fungal growth on building materials.

In this study, a set of methods was used in the diversity tracking of 42 toxigenic indoor Chaetomiaceae isolates found in buildings in Finland. The methods identified three species that constitute the Chaetomium globosum complex: Ch. globosum, Ch. cochliodes and Ch. rectangulare. Moreover, the mycotoxins produced by $\mathrm{Ch}$. globosum and $\mathrm{Ch}$. cochliodes were identified, and their biological activities were compared by cell-based bioassays. The species-specific sensitivity of the indoor Chaetomium isolates to indoor chemicals and biocides were also described.

\section{Results}

\subsection{Screening for Three Toxigenic Indoor Chaetomium-Like Isolates: Ch. globosum, Ch. cochliodes and Ch. rectangulare}

A combination of three screening methods was employed to detect cultivable toxigenic Chaetomium isolates from indoor dusts collected from eight problematic buildings in Finland. Single colonies $(n=220)$ picked from the cultivation plates were inspected for: (1) Toxicity of biomass suspensions in two bioassays: The results of the assays revealed that 130 colonies out of the 220 were screened to be toxic. (2) Production of ascomata: Inspection under a stereomicroscope and phase contrast microscope revealed that 42 colonies out of the 130 toxigenic colonies produced ascomata. (3) Fluorescence emitted by the biomass suspensions: When exitated with UV-light, biomass suspensions prepared from the 42 toxigenic ascomata-producing colonies emitted blue-green, blue, yellow-green or no fluorescence, as shown in Figure 1.

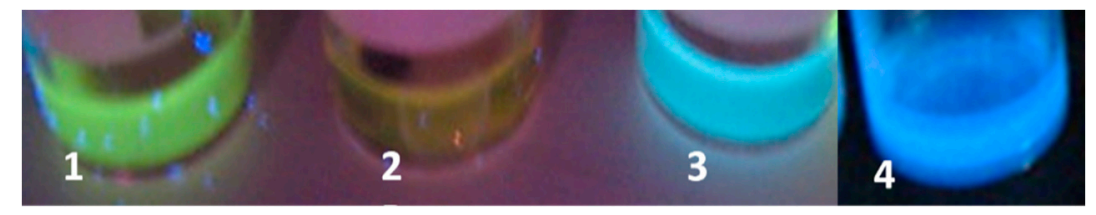

Figure 1. Fluorescence emissions of the biomass suspensions of selected Chaetomium-like isolates excited with UV light at $360 \mathrm{~nm}$ : (1) Chaetomium rectangulare MO15; (2) Ch. cochliodes OT7; (3) Ch. globosum HAS5; (4) Unidentified Chaetomium-like isolate Ch1/tu; and (F) Ch. cochliodes OT7b.

The 42 colonies characterized as toxigenic Chaetomium-like isolates were pure-cultured and categorized into four morphotypes based on the following: fluorescence emission of their biomass suspensions (Figure 1), morphology of their ascomata and size and shape of their ascospores (Figure 2). The strain codes, origin, sampling sites, morphotypes and fluorescence emissions, as well as the identified species and genera, are presented in Table 1.

Representative strains exhibiting the four different morphotypes (A-D) were identified down to the species/genus level (Table 1) as follows: (A) Ch. globosum exhibits a coiled, unbranched ascomatal hair, large globous ascospores and biomass suspension emitting blue-green fluorescence; (B) Ch. cochliodes exhibits straight, unbranched ascomatal hair, large oval ascospores and biomass suspensions emitting no fluorescence; (C) the unidentified Chaetomium-like isolates exhibit dichotomously branched ascomatal hair, small elongated ascospores and biomass suspensions emitting blue fluorescence; and (D) Ch. rectangulare exhibits branched ascomatal hair, large elongated ascospores and biomass suspensions emitting yellow-green fluorescence. Eleven isolates displaying the morphotypes A, B and D were very toxic in the BSMI and ICP assays, and they were identified as members of the Ch. globosum complex. 
Seven isolates obtained from seven buildings and displaying the morphotype A were identified as Ch. globosum. Two isolates displaying the morphotype B (OT7 and OT7b) and two other isolates displaying the morphotype $\mathrm{D}$ were identified as $\mathrm{Ch}$. cochliodes and Ch. rectangulare, respectively. Strains $\mathrm{Ch} 1 / \mathrm{tu}, \mathrm{Ch} 2 / \mathrm{tu}, \mathrm{Ch} 3 / \mathrm{tu}$ and Ch4/tu with morphotype C were only slightly toxic in the BSMI assay, nontoxic in the ICP assay and differed from the strains belonging to the Ch. globosum complex based on their small-sized ascospores. These strains were isolated from an inlet air filter and possibly came from the outdoor air (Table 1).

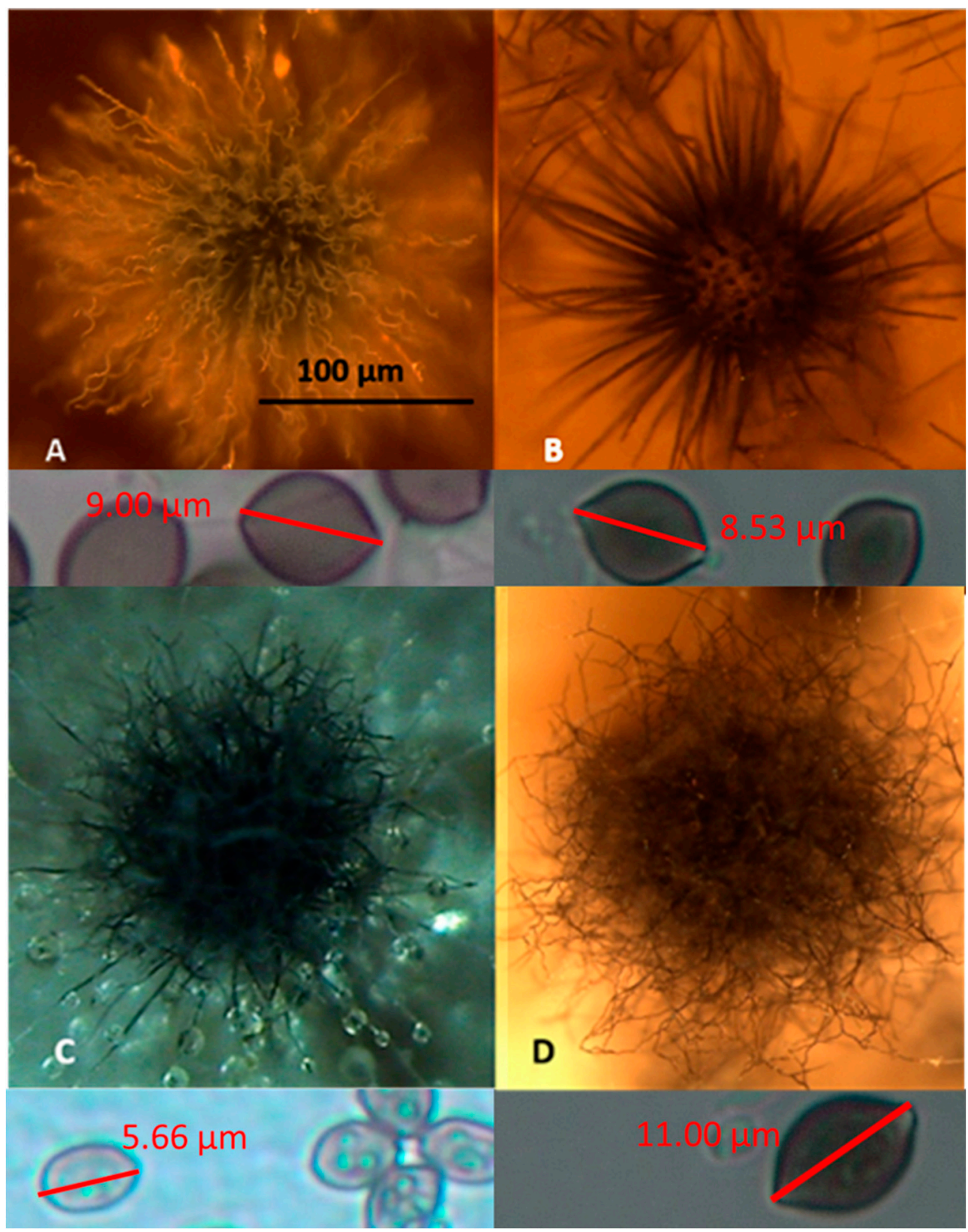

Figure 2. Stereomicrographs of the four morphotypes (A-D) exhibited by the 42 toxigenic Chaetomium-like isolates. (A) The Ch. globosum MTAV35 strain displayed a morphotype characterized by a curly ascomatal hair, and it produced $9 \mu \mathrm{m} \times 10 \mu \mathrm{m}$ globous ascospores. (B) The Ch. cochliodes OT7 strain exhibited a straight ascomatal hair and produced $8 \mu \mathrm{m} \times 9 \mu \mathrm{m}$ oval ascospores. (C) The unidentified Chaetomium-like strain Ch1/tu C exhibited straight, dichotomously branched ascomatal hair and produced $4 \mu \mathrm{m} \times 6 \mu \mathrm{m}$ oval ascospores. (D) The Ch. rectangulare MO15 strain exhibited a curly, dichotomously branched ascomatal hair and produced 6-7.5 $\mu \mathrm{m} \times 10-11 \mu \mathrm{m}$ elongated ascospores. 
Table 1. Characterization of 42 ascomata-producing indoor isolates obtained from eight buildings associated with indoor air-related health problems in Finland. The strains were screened to be toxic in the boar sperm motility inhibition and inhibition of cell proliferation bioassays.

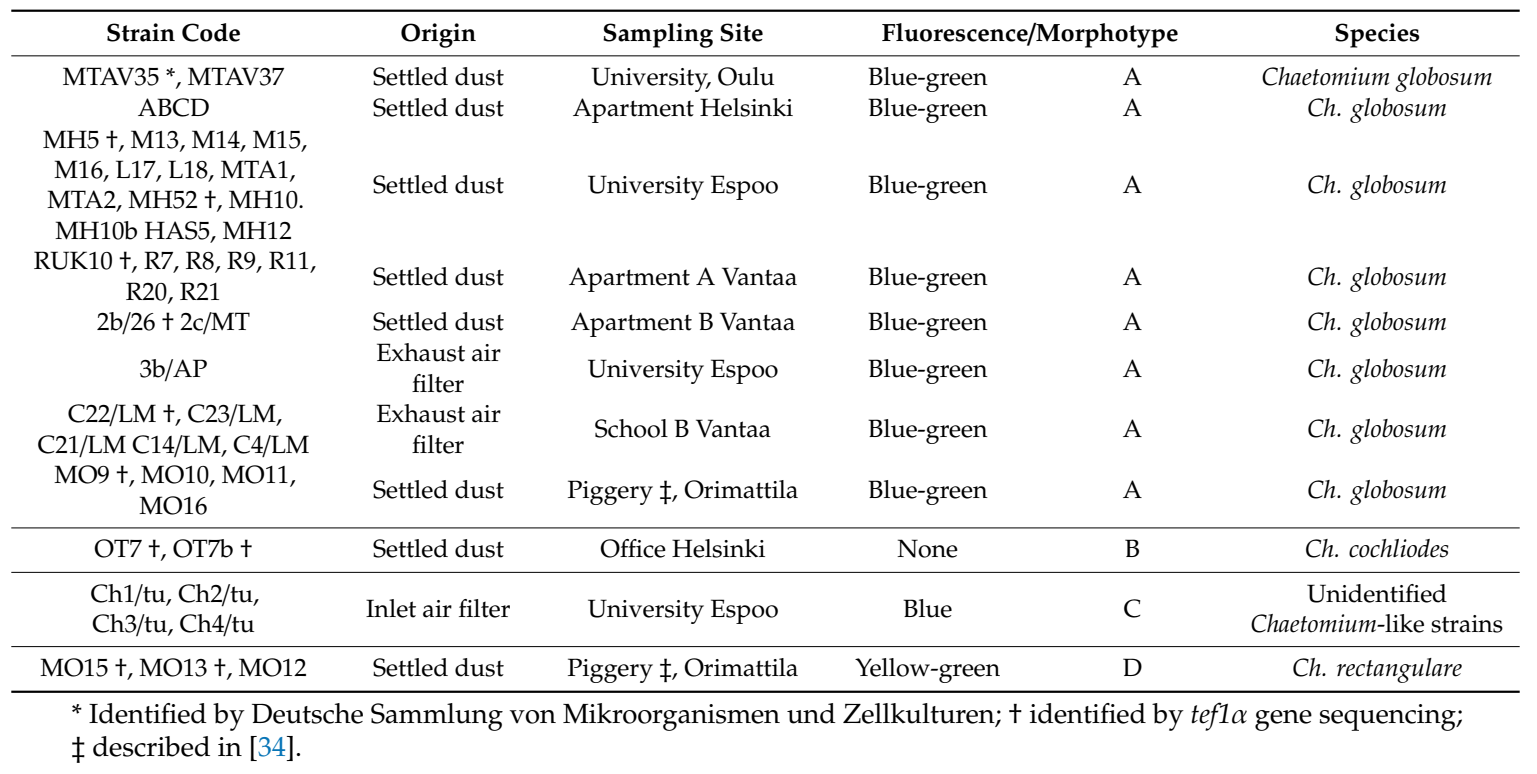

\subsection{Mycotoxins in the Fungal Extracts}

Compounds of the Ch. globosum and Ch. cochliodes ethanol extracts were identified using high-performance liquid chromatography-mass spectrometry (HPLC-MS). The HPLC-MS total ion chromatograms of the ethanol extracts of $\mathrm{Ch}$. globosum and $\mathrm{Ch}$. cochliodes and their compounds are shown in Figure 3A-F. The Ch. globosum strains (Figure 3A-D) total ion chromatograms highly resemble each other as well as the Ch. cochliodes strains (Figure 3E,F).

Figure S1A-F shows MS and MS/MS spectra of Ch. globosum RUK10 compounds 1-3 (Figure 3C). Compound 1 (Figure 3C) at $17.0 \mathrm{~min}$ of Ch. globosum RUK10 contained a protonated mass ion $[\mathrm{M}+\mathrm{H}]^{+}$ at $m / z 529.4$, a sodiated mass ion $[\mathrm{M}+\mathrm{Na}]^{+}$at $m / z 551.3$ and a mass ion of dimer $[2 \mathrm{M}+\mathrm{Na}]^{+}$at $\mathrm{m} / \mathrm{z} 1079.4$ of chaetoglobosins (Figure S1A). The MS/MS spectrum of the precursor mass ion at $\mathrm{m} / \mathrm{z}$ 529.9 produced mass ions at $m / z 511.3,457.2$ and 400.3 (Figure S1B), as reported by Xu et al. [35] for chaetoglobosin $\mathrm{C}$. The diagnostic fragmentation ion at $\mathrm{m} / \mathrm{z} 184.9$ indicated a tryptophan-containing moiety of chaetoglobosins (Figure S1B), as reported by Walsh et al. [36]. Compound 1 UV spectrum had maximum wavelengths at 220 and $280 \mathrm{~nm}$ (Figure S2A), similar to as reported for chaetoglobosin A [37]. However, compound 1 could not be identified to any specific member of chaetoglobosins family and therefore it was named as chaetoglobosin. Compound 2 of Ch. globosum RUK10 (Figure 3C) at 20.8 min contained a protonated mass ion $[\mathrm{M}+\mathrm{H}]^{+}$at $\mathrm{m} / \mathrm{z} 435.2$ and a sodiated mass ion $[\mathrm{M}+\mathrm{Na}]^{+}$ at $\mathrm{m} / \mathrm{z} 457.2$ and a mass ion of dimer $[2 \mathrm{M}+\mathrm{Na}]^{+}$at $\mathrm{m} / \mathrm{z} 891.3$ of chaetoviridin C (Figure S1C). The MS/MS spectrum of the precursor mass ion at $m / z 435.8$ produced mass ions at $m / z 417.1,389.1$ and 316.1 (Figure S1D). Chaetoviridin C had maximum wavelengths at 225, 294 and $390 \mathrm{~nm}$ (Figure S2B). Compound 3 of Ch. globosum RUK10 (Figure 3C) at 24.9 min contained a protonated mass ion $[\mathrm{M}+\mathrm{H}]^{+}$at $m / z 433.2$, a sodiated mass ion $[\mathrm{M}+\mathrm{Na}]^{+}$at $m / z 455.2$ and a mass ion of dimer $[2 \mathrm{M}+\mathrm{Na}]^{+}$at $\mathrm{m} / z 887.3$ of chaetoviridin A (Figure S1E). The MS/MS spectrum of the precursor mass ion at $m / z 433.9$ produced the mass ions at $\mathrm{m} / \mathrm{z} 333.1$ and 389.1 (Figure S1F), indicating the fragmentation of chaetoviridin A, as also reported by Larsen et al. [38]. Compound 3 also had similar UV spectrum, having maximum wavelengths at 228, 310 and $366 \mathrm{~nm}$ (Figure S2C), as reported for chaetoviridin A [38]. Other Ch. globosum strains MTAV35, HAS5 and ABCD contained compounds 1-3 at same retention time (Figure 3A,B,D) and had similar MS, MS/MS and UV spectra as described above for the Ch. globosum RUK10. 


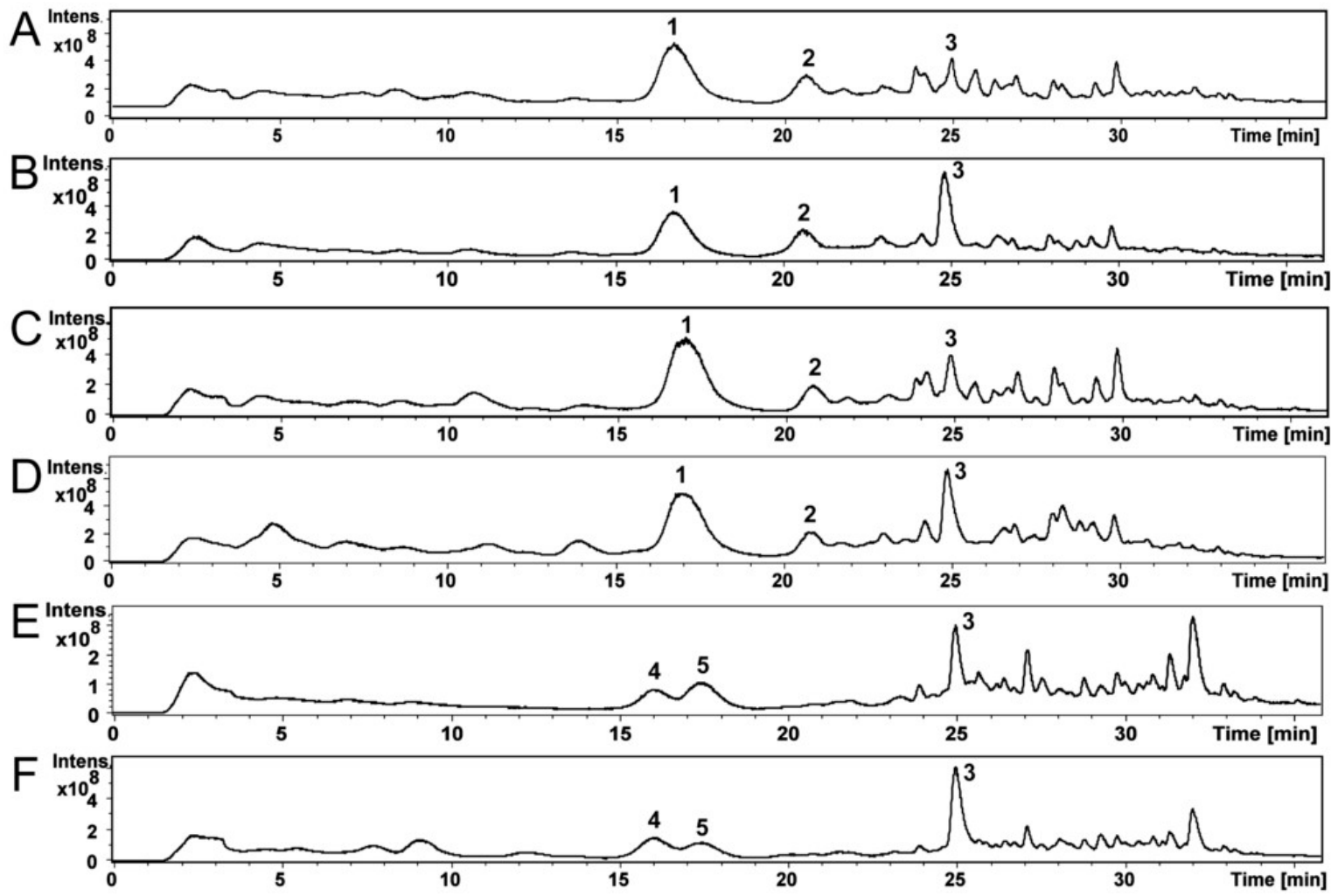

Figure 3. The HPLC-MS total ion chromatograms of the ethanol extracts of Ch. globosum strains MTAV35 (A), HAS5 (B), RUK10 (C) and ABCD (D) and Ch. cochliodes strains OT7 (E) and OT7b (F) and their compounds $\mathbf{1}-\mathbf{5}$.

Compound 4 of the Ch. cochliodes OT7 (Figure 3E) at 16.0 min contained a protonated mass ion $[\mathrm{M}+\mathrm{H}]^{+}$at $m / z 435.2$ and a sodiated mass ion $[\mathrm{M}+\mathrm{Na}]^{+}$at $m / z 457.2$ and a mass ion of dimer $[2 \mathrm{M}+\mathrm{Na}]^{+}$at $\mathrm{m} / \mathrm{z} 891.2$ of chaetomugilin D (Figure S1G). The MS/MS spectrum of the precursor mass ion at $m / z 435.9$ produced the mass ions at $m / z 417.2,389.2$ and 361.1 (Figure S1H). Compound 4 had UV spectrum with the maximum wavelengths at 220, 295 and $386 \mathrm{~nm}$ (Figure S2D), similar to as reported for chaetomugilin D by McMullin et al. [39]. Compound 5 of the Ch. cochliodes OT7 (Figure 3E) at 17.4 min contained a protonated mass ion $[\mathrm{M}+\mathrm{H}]^{+}$at $m / z 711.2$, a sodiated mass ion $[\mathrm{M}+\mathrm{Na}]^{+}$at $\mathrm{m} / \mathrm{z} 733.2$ and $[\mathrm{M}-\mathrm{S} 2+\mathrm{Na}]^{+}$at $\mathrm{m} / \mathrm{z} 669.3$ and a mass ion of $\operatorname{dimer}[2 \mathrm{M}+\mathrm{Na}]^{+}$at $\mathrm{m} / \mathrm{z} 1443.0$ of chaetomin (Figure S1I). The MS/MS spectrum of the precursor mass ion at $\mathrm{m} / \mathrm{z} 711.7$ produced the mass ion at $m / z 645.2$ indicating neutral loss of $\mathrm{H}_{2} \mathrm{~S}_{2}$ producing the mass ion $\left[\mathrm{M}-\mathrm{H}_{2} \mathrm{~S}_{2}+\mathrm{H}\right]^{+}$ (Figure S1J). A complementary pair of fragment ions of the precursor mass ion at $\mathrm{m} / \mathrm{z} 711.7$ were found at $\mathrm{m} / \mathrm{z} 348.0$ and 364.1. The fragment ion at $\mathrm{m} / \mathrm{z} 298.0$ represent loss of a HSSH of mass ion $\mathrm{m} / \mathrm{z}$ 364.0 and fragment ion at $m / z 282.0$ represent loss of HSSH of mass ion $\mathrm{m} / \mathrm{z} 348.0$, as also reported by $\mathrm{Wu}$ et al. [40] for chaetomin. UV spectrum of chaetomin had maximum wavelengths at 220, 275 and $285 \mathrm{~nm}$ (Figure S2E). Compound 3, chaetoviridin A, which was also found from Ch. globosum strains, was detected in Ch. cochliodes OT7 (Figure 3E) at $24.9 \mathrm{~min}$ and contained a protonated mass ion $[\mathrm{M}+\mathrm{H}]^{+}$at $m / z 433.2$, a sodiated mass ion $[\mathrm{M}+\mathrm{Na}]^{+}$at $m / z 455.2$ and a mass ion of dimer $[2 \mathrm{M}+\mathrm{Na}]^{+}$ at $\mathrm{m} / \mathrm{z} 887.3$ (Figure S1K). The MS/MS spectrum of the precursor mass ion at $\mathrm{m} / \mathrm{z} 433.8$ produced the mass ions at $\mathrm{m} / \mathrm{z} 333.0$ and 389.1 (Figure S1L). The Ch. cochliodes OT7b also contained compounds 3-5 at the same retention time (Figure 3F) and had similar MS, MS/MS and UV spectra as described above for Ch. cochliodes OT7.

Based on retention times, UV spectra, MS and MS/MS mass spectrometric data and the earlier published UV spectra and mass spectrometric data, compounds 1-3 of the Ch. globosum strains MTAV35, HAS5, RUK10 and ABCD were identified as chaetoglobosin and chaetoviridin C and A, respectively, 
while compounds $\mathbf{3}-\mathbf{5}$ of the $\mathbf{C h}$. cochliodes strains OT7 and OT7b were identified as chaetomugilin $\mathrm{D}$, chaetomin and chaetoviridin A, respectively (Table 2). The amounts of mycotoxins present in the ethanol extracts were calculated from the total absorbance $(220 \mathrm{~nm})$ of the HPLC-UV chromatograms (Table 2).

Table 2. Toxic responses of ethanol-soluble compounds in the Chaetomium globosum and Ch. cochliodes extracts as determined by the boar sperm bioassays $\mathrm{BSMI}_{\mathrm{M}}$ and $\mathrm{SMID}_{\mathrm{M}}$ and by the cytostatic ICP assay involving porcine kidney cells (PK-15) and murine neuroblastoma cells (MNA). All target cells were exposed at $37^{\circ} \mathrm{C}$.

\begin{tabular}{|c|c|c|c|c|c|c|c|}
\hline \multirow{4}{*}{ Strain } & \multirow{4}{*}{ Code } & \multicolumn{4}{|c|}{$\mathrm{EC}_{50}\left(\mu \mathrm{g}\right.$ dry wt $\left.\mathrm{mL}^{-1}\right)$} & \multirow{4}{*}{$\begin{array}{l}\text { Identified } \\
\text { Metabolite }\end{array}$} & \multirow{4}{*}{$\begin{array}{c}\text { Estimated } \\
\text { Concentration } \\
\left(\mathrm{mg} \mathrm{mL}^{-1}\right)\end{array}$} \\
\hline & & BSMI $_{M}$ & SMID $_{M}$ & \multicolumn{2}{|c|}{ ICP } & & \\
\hline & & \multicolumn{2}{|c|}{ Boar Sperm } & PK-15 & MNA & & \\
\hline & & $20 \mathrm{~min}$ & $2 \mathrm{~h}$ & 2 days & 2 days & & \\
\hline \multicolumn{8}{|l|}{ Biomasses } \\
\hline \multicolumn{8}{|c|}{ Group I blue green fluorescent } \\
\hline \multirow[t]{3}{*}{ Ch. globosum } & MTAV35 & 5 & 450 & 40 & 20 & chaetoglobosin & 3.4 \\
\hline & & & & & & chaetoviridin A & 0.02 \\
\hline & & & & & & chaetoviridin $C$ & 0.2 \\
\hline Ch. globosum & MTAV37 & 10 & 350 & 30 & 15 & No data & \\
\hline \multirow[t]{3}{*}{ Ch. globosum } & HAS5 & 5 & 310 & 50 & 25 & chaetoglobosin & 3.9 \\
\hline & & & & & & chaetoviridin A & 0.5 \\
\hline & & & & & & chaetoviridin $C$ & 0.2 \\
\hline \multirow[t]{3}{*}{ Ch. globosum } & RUK10 & 5 & 300 & 20 & 10 & chaetoglobosin & 4.2 \\
\hline & & & & & & chaetoviridin A & 0.04 \\
\hline & & & & & & chaetoviridin $C$ & 0.05 \\
\hline \multirow[t]{3}{*}{ Ch. globosum } & $\mathrm{ABCD}$ & 5 & 450 & 30 & 15 & chaetoglobosin & 4.24 \\
\hline & & & & & & chaetoviridin A & 0.3 \\
\hline & & & & & & chaetoviridin $C$ & 0.05 \\
\hline \multicolumn{8}{|c|}{ Group II Non-fluorescent } \\
\hline \multirow[t]{6}{*}{ Ch. cochliodes } & OT7 & 10 & 480 & 0.5 & 0.5 & chaetomin & 1.3 \\
\hline & & & & & & chaetoviridin A & 0.13 \\
\hline & & & & & & chaetomugilin D & 0.02 \\
\hline & OT7b & 10 & 480 & 0.8 & 0.8 & chaetomin & 1.2 \\
\hline & & & & & & chaetoviridin A & 0.3 \\
\hline & & & & & & chaetomugilin D & 0.2 \\
\hline Exudate & $2 \mathrm{c} / \mathrm{MT}$ & & & & & \multicolumn{2}{|l|}{ Chaetoglobosin ${ }^{1}$} \\
\hline \multicolumn{2}{|c|}{ Reference mycotoxin } & & & & & Biolog & ctivity \\
\hline \multicolumn{2}{|c|}{$\begin{array}{c}\text { Alamethicin } \\
\text { (Trichoderma arundinaceum) }\end{array}$} & 5 & 1 & 8 & 8 & \multicolumn{2}{|c|}{$\begin{array}{l}\text { Lethal toxin, } \mathrm{K}^{+} \text {and } \mathrm{Na}^{+} \text {ion channel } \\
\text { former }[41]\end{array}$} \\
\hline \multicolumn{2}{|c|}{$\begin{array}{c}\text { Chaetoglobosin A } \\
\text { (Ch. globosum) }\end{array}$} & 1 & 12 & 3 & 1 & \multicolumn{2}{|c|}{$\begin{array}{l}\text { Sublethal toxin, inhibitor of glucose } \\
\text { transport [42] }\end{array}$} \\
\hline \multicolumn{2}{|c|}{$\begin{array}{c}\text { Citrinin } \\
\text { (Penicillium citrinum) }\end{array}$} & $>100$ & 50 & 10 & 10 & \multicolumn{2}{|c|}{ Cytostatic toxin, nephrotoxic [41] } \\
\hline \multicolumn{2}{|c|}{ Sterigmatocystin (Aspergillus spp.) } & $>20$ & $>20$ & 0.5 & & \multicolumn{2}{|c|}{$\begin{array}{l}\text { Cytostatic toxin, inhibitor of protein } \\
\text { synthesis [42] }\end{array}$} \\
\hline \multicolumn{2}{|c|}{$\begin{array}{c}\text { Valinomycin } \\
\text { (Streptomyces griseus) }\end{array}$} & 0.0001 & 70 & 14 & & \multicolumn{2}{|c|}{$\begin{array}{l}\text { Sublethal toxin, mitochondrial toxin, } \\
\text { potassium carrier ionophore [43] }\end{array}$} \\
\hline
\end{tabular}

\subsection{Mycotoxin and Toxicity Profiles of the Ch. globosum and Ch. cochliodes Isolates}

Ethanol extracts containing $10 \mathrm{mg}$ ethanol-soluble dry substances dissolved in $1 \mathrm{~mL}$ ethanol were prepared from plate-grown biomass (wet wt, ca. 200-400 mg) of the selected Ch. globosum and Ch. cochliodes strains. The ethanol extracts of the Ch. globosum strains emitted green fluorescence, similar to the biomass lysates. On the contrary, no fluorescence was observed from the extracts of the Ch. cochliodes strains. The chemical analyses (Table 3) indicated that the plate-grown biomass of the Ch. globosum strains contained ca. $1 \%$ of chaetoglobosin, whereas the chaetomin concentration was only $0.25 \%$ of the collected biomass. 
Table 3. Effective concentrations $\left(\mathrm{EC}_{50} \mu \mathrm{g} \mathrm{mL} \mathrm{m}^{-1}\right.$ ) for lethal and sublethal toxicity recorded in resting porcine spermatozoa and kidney cells (PK-15) exposed to ethanol extracts obtained from the Chaetomium globosum strains and selected reference mycotoxins.

\begin{tabular}{|c|c|c|c|c|c|c|c|c|}
\hline \multirow{5}{*}{ Strain Code } & \multicolumn{6}{|c|}{$\mathrm{EC}_{50} \mu \mathrm{g} \mathrm{mL}^{-1}$} & & \\
\hline & \multicolumn{6}{|c|}{ Boar Sperm } & \multicolumn{2}{|l|}{ PK-15 } \\
\hline & \multicolumn{4}{|c|}{ Lethal Toxicity } & \multicolumn{3}{|c|}{ Sublethal Toxicity } & \\
\hline & \multicolumn{2}{|c|}{$\mathrm{SMID}_{\mathrm{R}}$} & \multicolumn{2}{|c|}{$\mathrm{BSMI}_{\mathrm{R}}$} & \multicolumn{2}{|c|}{ Depletion of $\Delta \Psi_{\mathrm{m}}$} & \multirow{2}{*}{$\begin{array}{c}\text { Acceleration of glycolysis } \\
1 \text { day }\end{array}$} & \multirow{2}{*}{$\begin{array}{c}\text { Acidosis } \\
2 \text { days }\end{array}$} \\
\hline & 2 days & 4 days & 2 days & 4 days & 2 days & 4 days & & \\
\hline MTAV35 & $>20$ & $>20$ & 3 & 3 & 6 & 3 & None & None \\
\hline MTAV37 & $>20$ & $>20$ & 4 & 4 & 4 & 4 & None & None \\
\hline \multicolumn{9}{|c|}{ Reference toxins } \\
\hline \multicolumn{9}{|c|}{ Lethal toxin forming ion channels in the plasma membrane } \\
\hline Alamethicin & 0.2 & & 0.2 & & 0.2 & & None & None \\
\hline \multicolumn{9}{|c|}{ Sublethal toxin inhibiting glucose transport } \\
\hline Chaeto-globosin A & $>20$ & & 1 & & 2 & & None & None \\
\hline \multicolumn{9}{|c|}{ Sublethal mitochondrial toxins } \\
\hline Enniatin B & $>50$ & & 5 & & 5 & & $5(50) *$ & 5 \\
\hline Moniliformin & ND & & 2 & & None & & $4(40) *$ & 4 \\
\hline Valinomycin & 5 & & & 05 & 0.0 & 005 & $0.005(5) *$ & 0.005 \\
\hline
\end{tabular}

The biological activities of the ethanol extracts of the indoor Ch. globosum and Ch. cochliodes strains were indicated by their toxicological profiles obtained by the three bioassays. These bioassays measured the sublethal $\left(\mathrm{BSMI}_{\mathrm{M}}\right)$ and lethal $\left(\mathrm{SMIDA}_{\mathrm{M}}\right)$ toxicities in exposed motile spermatozoa, as well as the cytostatic toxicity (ICP) using continuous (PK-15) and malignant (murine neuroblastoma [MNA]) cell lines (Table 3).

The tested ethanol extracts of the Chaetomium strains exhibited two toxicity profiles based on the differences in $\mathrm{EC}_{50}$ concentrations of the ethanol-soluble dry solids obtained by the three assays (Table 2). The ethanol extracts of Group I-consisting of the Ch. globosum strains MTAV35, HAS5, RUK10 and ABCD—contained high concentrations of chaetoglobosin at $4 \mathrm{mg} \mathrm{mL}^{-1}(>85 \% w / v$ of the identified mycotoxins), but chaetomin was not detected. The extracts in Group I showed similar $\mathrm{EC}_{50}$ concentrations in the sublethal $\mathrm{BSMI}_{\mathrm{M}}$ and in the ICP assays-5-10 $\mu \mathrm{g} \mathrm{mL}^{-1}$-which is 100 times lower than the $\mathrm{EC}_{50}$ concentrations in the lethal $\mathrm{SMID}_{\mathrm{M}}$ assay $\left(300-450 \mu \mathrm{g} \mathrm{mL}^{-1}\right)$. This toxicity profile indicated that the sublethal and cytostatic toxicities were similarly strong, and it was consistent with the toxicity profile of pure chaetoglobosin A (but it differed from that of the lethal toxin alamethicin and the sublethal mitochondrial toxin valinomycin).

In Group II, the extracts obtained from the Ch. cochliodes strains OT7 and OT7b contained high chaetomin concentrations $\left(1 \mathrm{mg} \mathrm{mL}{ }^{-1} ;>70 \% w / v\right.$ of the identified mycotoxins), whereas chaetoglobosin and chaetoviridins $\mathrm{C}$ were undetectable and chaetoviridin $\mathrm{A}$ and chaetomugilin $\mathrm{D}$ were detected at low concentration $\left(0.02-0.3 \mathrm{mg} \mathrm{mL}^{-1}\right)$. These extracts exhibited the highest toxicity in the ICP assays, with an $\mathrm{EC}_{50}$ of $<1 \mu \mathrm{g} \mathrm{mL} \mathrm{m}^{-1}$. This result indicates a strong cytostatic activity similar to that exhibited by pure sterigmatocystin and citrinin (Table 2). Moreover, the extracts of OT7 and OT7b exhibited sublethal motility-inhibiting effect on the exposed spermatozoa. The sublethal activity was indicated by the $30-50$ times lower $\mathrm{EC}_{50}$ concentration in the $\mathrm{BSMI}_{\mathrm{M}}$ assay $\left(10 \mu \mathrm{g} \mathrm{mL} \mathrm{L}^{-1}\right)$ compared with the $\mathrm{EC}_{50}$ concentrations of $300-500 \mu \mathrm{g} \mathrm{mL}^{-1}$ in the $\mathrm{SMID}_{\mathrm{M}}$ assay that indicated lethal toxicity.

Chaetoviridins A and C and chaetomugilin D were detected in low amounts (3-15\%) in the ethanol-soluble extracts of each of the Chaetomium strains screened for toxicity (Table 3). Therefore, the main difference between Groups I and II was the presence of either chaetoglobosin or chaetomin in their ethanol-soluble extracts. The extract from strain RUK10 containing the smallest amounts of chaetoviridins $\left(<0.09 \mathrm{mg} \mathrm{mL}^{-1}\right)$ exhibited the smallest $\mathrm{EC}_{50}$ concentration (i.e., the highest toxicity in the BSMI and ICP assays among the tested Ch. globosum strains). Considering these results, 
we hypothesized that the chaetoglobosins were the main cause of the sublethal sperm motility inhibition and of the cytostatic effect of the Ch. globosum ethanol extract. We also hypothesized that chaetomin in the $\mathrm{Ch}$. cochliodes extracts caused a considerably strong cytostatic toxicity (as indicated by the PK-15 and MNA cell proliferation) and that chaetomin exposure caused the motility-inhibiting activity in the exposed sperm cells.

The exudate of Ch. globosum 2c/MT (Table 3) emitted blue-green fluorescence and was found to contain chaetoglobosin. Moreover, the fluorescent exudates of MO9 (Figure 4) were found toxic in bioassays. Based on these results, we hypothesized that the chaetoglobosin produced by strain 2c/MT and the toxin produced by strain MO9 may be excreted as liquid exudates.
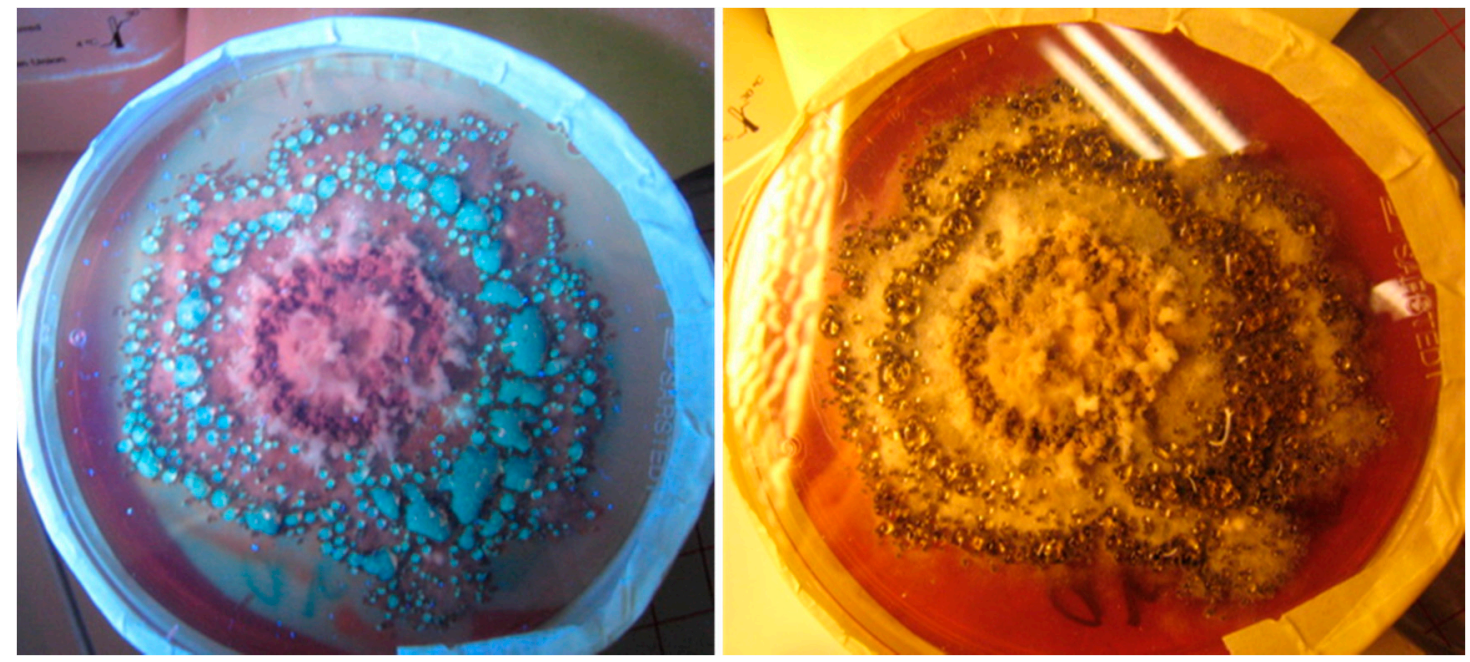

Figure 4. Pure culture of Chaetomium globosum imaged under UV (left) and visible light (right). Strain MO9 was grown on malt extract agar (MEA) at $24{ }^{\circ} \mathrm{C}$ for two weeks. Exudate-containing vesicles emitting blue-green fluorescence are shown in the left panel.

\subsection{Characterization of the Toxicological Profile of Pure Chaetoglobosin A and Chaetoglobosin-Containing Extracts}

The long-term effects of exposure to chaetoglobosin A and to the chaetoglobosin-containing extracts of the Ch. globosum MTAV35 and MTAV37 strains were measured in resting sperm cells exposed at $24{ }^{\circ} \mathrm{C}$ for two days. Three criteria were assessed: (1) the motility inhibition of resting boar spermatozoa $\left(\mathrm{BSMI}_{\mathrm{R}}\right)$; (2) the change in mitochondrial membrane potential $(\Delta \Psi)$ observed using the potentiometric dye JC-1; and (3) the plasma membrane integrity $\left(\mathrm{SMID}_{\mathrm{R}}\right)$ observed using the viability stain calcein-AM + propidium iodide (PI). Chaetoglobosin A and the Ch. globosum extracts of the MTAV35 and MTAV37 strains exhibited equally low $\mathrm{EC}_{50}$ concentrations $\left(3-4 \mu \mathrm{g} \mathrm{mL}{ }^{-1}\right.$ ) in the motility inhibition assay and mitochondrial depolarization assay, during which the resting spermatozoa were exposed. By contrast, the $\mathrm{EC}_{50}$ concentrations in the $\mathrm{SMID}_{\mathrm{R}}$ assays, which measured the lethal damages in plasma membrane after incubation for two days, were $>50$ times higher (Figure 5 and Table 3). Therefore, chaetoglobosin A and the chaetoglobosin-containing extracts also provoked a toxic response after the prolonged exposure, indicating that their sublethal toxicity differs from the lethal toxic responses elicited by alamethicin [41]. 

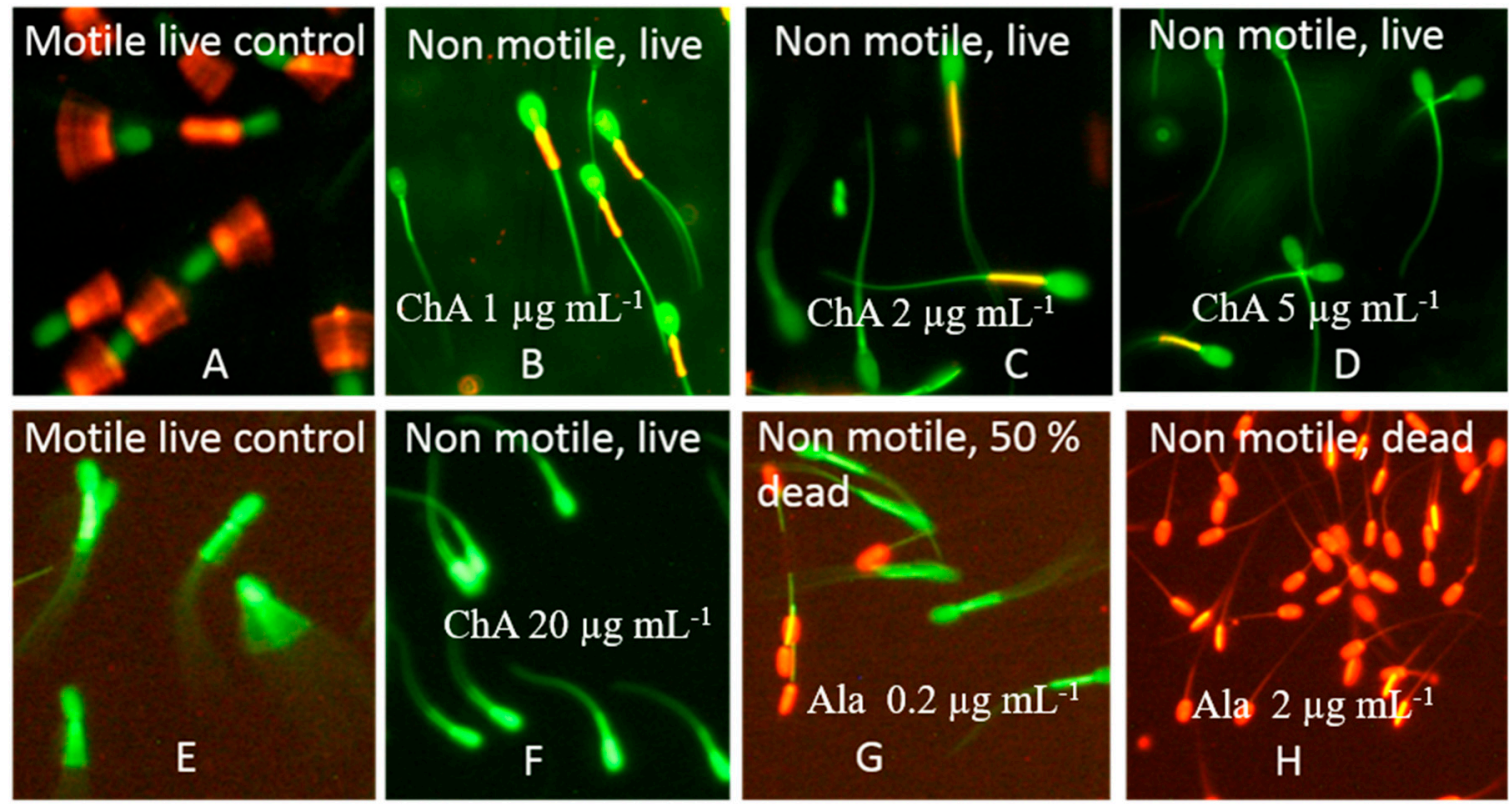

Figure 5. Fluorescence micrographs showing the test results for mitochondrial membrane potential $\Delta \Psi_{\mathrm{m}}$ and $\mathrm{SMID}_{\mathrm{R}}$ assay. Boar spermatozoa were exposed to chaetoglobosin A (ChA) for two days at $24{ }^{\circ} \mathrm{C}$. The sperm cells were stained with the membrane potentiometric dye JC-1 (top) and with the live-dead stain calcein-AM plus propidium iodide (PI) (bottom). The motile sperm cells in (A) and (E) were exposed to $1 \%$ ethanol as negative controls. (B-D,F) The sperm cells immobilized by ChA. The sperm cells in (A) exhibit high $\Delta \Psi_{\mathrm{m}}$ as indicated by the orange emission in the midpiece of the sperm flagellum; the green-staining sperm cells in (E) exhibit intact plasma membranes impermeable to the red stain PI. The red-staining sperm cells have lost their plasma membrane integrity and became permeable to PI. The sperm cells in $(\mathbf{G}, \mathbf{H})$ (positive controls for lethal toxicity) were exposed to alamethicin (Ala).

The mitochondria were depolarized in sperm cells exposed to sublethal concentrations of chaetoglobosin A (Figure 5) and to the chaetoglobosin-containing extracts (Table 3). This observation aroused the suspicion regarding mitochondrial toxicity. The mitochondrial toxicity of the extracts containing chaetoglobosin was assessed by measuring the accelerated glucose consumption in resting PK-15 cells. Exposure to these chaetoglobosin-containing extracts at concentrations between 50 and $0.5 \mu \mathrm{g} \mathrm{mL}{ }^{-1}$ did not promote the acceleration of glycolysis in the exposed PK-15 cells. By contrast, the positive controls for mitochondrial toxicity-enniatin B, moniliformin and valinomycin at sublethal concentrations of $1.5,4$ and $5 \mathrm{ng} \mathrm{mL}^{-1}$, respectively-promoted the acceleration of glycolysis. This result indicates that no impaired mitochondrial functions based on the acceleration of glycolysis in the PK-15 cells exposed to chaetoglobosins [42] were detected. The chaetoglobosin-containing extract thus exhibited a unique sublethal profile which differed from that exhibited by the sublethal mitochondrial toxins valinomycin [43], enniatin B [44] and moniliformin [11] in terms of bioactive responses in the set of tests used.

\subsection{Resistance of Indoor Chaetomium Strains to Biocides and the Wetting Agent Genapol-X-080}

Eleven Ch. globosum isolates obtained from urban indoor environments, one Ch. globosum strain obtained from a piggery and two urban indoor $\mathrm{Ch}$. cochliodes strains were tested for their resistance to biocides and Genapol-X080 (a wetting agent used indoors). Two mammalian cell lines, PK-15 and MNA, as well as representative strains of the genera Trichoderma, Aspergillus, Paecilomyces and Penicillium, were used as reference strains $(n=36)$. The endpoints measured using the microscopic germ tube test (Figure S3) and based on turbidity and fluorescence emission, resporulation (Figures S4 and S5) and glucose consumption were similar for the tested chemicals, namely borax, Boracol, polyhexamethylene biguanide hydrochloride (PHMB), Genapol-X080, phenoxyethanol, chloramine and triclosan. The SDs 
among 3-4 independent measurements were between $38 \%$ and $\leq 28.5 \%$. The toxic endpoints for conidial germination and for resporulation for all chemicals were similar, except for Genapol-X080 where resporulation was inhibited at concentrations lower by 100 times relative to the concentrations in the other endpoints. The results are shown in Figures S4-S6 and in Table 4. The EC 50 values in Table 4 represent a value between $\mathrm{EC}_{0}$ and $\mathrm{EC}_{100}$ and the median of four independent measurements with five methods. Genapol-X080 differed from the other tested chemicals in that the endpoints for conidial germination measured based on germ tube test, turbidity, fluorescence emission and glucose consumption were $>100$ times higher than the endpoint for resporulation. The high sensitivity to Genapol-X080 by the Ch. globosum HAS5 strain is illustrated in Figure S4; the toxic endpoint of Genapol-X080 expressed as the average $\mathrm{EC}_{50}$ values of four measurements was $44 \mu \mathrm{g} \mathrm{mL}^{-1}(\mathrm{SD} \pm 12.5)$. The reference strain Trichoderma atroviride $\mathrm{H} 1 / 226$ exhibited an $\mathrm{EC}_{50}$ value of $\geq 50,000 \mu \mathrm{g} \mathrm{mL}-1$ for Genapol-X080.

The high sensitivity of the Ch. globosum strain MTAV35 to Genapol-X080 relative to that of the selected Aspergillus reference strains is visualized in Figure S5. The figure shows bright fluorescence emitted by all dilutions in Figure S5A,B (Row 4). No fluorescence was emitted by the dilutions in Figure S5C (Row 4). This result illustrates that the ascospores of the Ch. globosum strain MTAV35 were inhibited in Genapol-X080 dilutions stronger by over 1000 times compared with the conidia of A. westerdijkiae PP2 and A. calidoustus MH4. Moreover, conidial germination was indicated by the increased turbidity in Figure S5D-F, where the three Aspergilli were resistant to the highest concentration-50,000 $\mu \mathrm{g} \mathrm{mL}{ }^{-1}$ —which is the smallest Genapol-X080 dilution in Row 4.

Figure S5G-I shows no resporulation in Row 4 at Genapol-X080 concentrations higher than 200-400 $\mu \mathrm{g} \mathrm{mL}^{-1}$. The microscopic inspection and turbidimetric estimation revealed the conidial germination in all tested dilutions in Row 4, but resporulation was obviously inhibited or delayed by Genapol-X080. Genapol-X080 differed from the other tested chemicals in that the endpoints for conidial germination were $>100$ times larger than those for resporulation.

The twelve blue/green fluorescent Ch. globosum, the blue fluorescent unidentified Chaetomium-like strain Ch1/tu and the somatic cell lines were 1000 times more sensitive to Genapol-X080 $\left(\mathrm{EC}_{50} \leq 50 \mu \mathrm{g} \mathrm{mL}{ }^{-1}\right)$ than the two non-fluorescent $C h$. cochliodes and the yellow fluorescent Ch. rectangulare strains $\left(\mathrm{EC}_{50} \geq 50,000 \mu \mathrm{g} \mathrm{mL} \mathrm{m}^{-1}\right)$. In addition, our results indicate that the Ch. globosum strains and the somatic cell lines were 1000 times more sensitive to Genapol-X080 than the reference strains belonging to Trichoderma, Aspergillus, Paecilomyces and Penicillium (Figures S4, S5 and Table 4).

All tested fungal strains, including the Ch. globosum strains, were more resistant to borax, Boracol, PHMB and chloramine than the somatic cell lines MNA and PK-15. Phenoxyethanol and triclosan exhibited the smallest differences in terms of the sensitivity of fungi and somatic cells towards them. The most resistant to borax and Boracol were the Ch. globosum strains and the Aspergillus reference strains. The Aspergillus strains also exhibited a high resistance to PHMB, whereas the Trichoderma strains exhibited a high resistance to triclosan and chloramine. No difference in resistance pattern was observed between the indoor and outdoor Trichoderma atroviride strains. The opportunistic human pathogenic T. longibrachiatum and T. citrinoviride were more sensitive to PHMB and Boracol than the T. atroviride strains.

In summary, the tested blue/green fluorescent Ch. globosum strains isolated from different buildings exhibited a uniform mycotoxin profile, a uniform sublethal toxicological profile and a uniform resistance profile towards detergents and biocides for indoor use. The two non-fluorescent Ch. cochliodes strains differed in all four characteristics from the tested Ch. globosum strains. 
Table 4. Resistance to biocides and to the wetting agent Genapol-X-080 of the Chaetomium-like strains and the selected indoor and outdoor fungal strains and mammalian cell lines. Resistance was measured based on conidial and ascospore germination, which were evaluated in terms of the formation of germ tubes as observed under a light microscope, increased turbidity, fluorescence emission and resporulation.

\begin{tabular}{|c|c|c|c|c|c|c|c|}
\hline \multirow{2}{*}{ Strain Code } & \multicolumn{7}{|c|}{$\mathrm{EC}_{50}\left(\mu \mathrm{g} \mathrm{mL}^{-1}\right)$} \\
\hline & Borax & Boracol & РHMB & Genapol-X080 & Phenoxy-ethanol & Chloramine & Triclosan \\
\hline \multicolumn{8}{|c|}{ Indoor Ch. globosum strains } \\
\hline MTAV35 & 5000 & 100 & 4 & $<50$ & 700 & 1200 & 2 \\
\hline MTAV37 & 5000 & 100 & 4 & $<50$ & 700 & 1200 & 4 \\
\hline HAS5 & $>5000$ & 100 & 8 & 50 & 1500 & 2500 & 2 \\
\hline $2 b / 26$ & $>5000$ & 100 & 8 & 50 & 1500 & 2500 & 4 \\
\hline MH 52 & 5000 & 50 & 4 & $<50$ & 1500 & 1200 & 2 \\
\hline RUK10 & 5000 & 100 & 4 & $<50$ & 1500 & 2500 & 2 \\
\hline $\mathrm{ABCD}$ & 5000 & 100 & 4 & $<50$ & 1500 & 1200 & 4 \\
\hline MO9 & $>5000$ & 100 & 4 & $<50$ & 700 & 2500 & 2 \\
\hline $2 \mathrm{c} / \mathrm{MT}$ & $>5000$ & 100 & 8 & 50 & 1500 & 2500 & 4 \\
\hline C22/LM & $>5000$ & 100 & 8 & 50 & 1500 & 2500 & 4 \\
\hline 3b/AP & $>5000$ & 100 & 8 & 50 & 1500 & 2500 & 4 \\
\hline \multicolumn{8}{|c|}{ Indoor Ch. cochliodes strains } \\
\hline OT7 & 750 & 50 & 8 & $>5000$ & 3000 & ND & 4 \\
\hline OT7b & 750 & 50 & 8 & $>5000$ & 3000 & ND & 4 \\
\hline \multicolumn{8}{|c|}{ Indoor Ch. rectangulare strains } \\
\hline M015 & 5000 & 100 & 4 & 50,000 & 1500 & 1200 & 2 \\
\hline Mo13 & $>5000$ & 100 & 4 & 50,000 & 1500 & 1200 & 2 \\
\hline \multicolumn{8}{|c|}{ Reference strains } \\
\hline $\mathrm{CH} 1 / \mathrm{tu}$ & 1200 & 100 & 4 & $<50$ & 1500 & 1200 & 2 \\
\hline \multicolumn{8}{|c|}{ Strains that could grow at $37^{\circ} \mathrm{C}$} \\
\hline & \multicolumn{7}{|c|}{ Indoor strains of Aspergillus section Nigri } \\
\hline Asp21 & $\geq 5000$ & 1600 & 30 & $>50,000$ & 3000 & 1200 & 30 \\
\hline Asp33b & $\geq 5000$ & 1600 & 30 & $>50,000$ & 3000 & 1200 & 16 \\
\hline \multirow[t]{2}{*}{ Asp 32} & $\geq 5000$ & 1600 & 60 & $>50,000$ & 3000 & 1200 & 16 \\
\hline & \multicolumn{7}{|c|}{ Indoor strains of Aspergillus section Flavi } \\
\hline $7 \mathrm{D}$ & 2500 & 200 & 120 & $>50,000$ & 1500 & 600 & 8 \\
\hline $1 / 37$ & 5000 & 1600 & 120 & $>50,000$ & 1500 & 600 & 8 \\
\hline \multicolumn{8}{|c|}{ Indoor Aspergillus calidoustus strain } \\
\hline MH4 & 5000 & 200 & 8 & $>5000$ & 3200 & ND & 16 \\
\hline \multicolumn{8}{|c|}{ Indoor Paecilomyces variotii strains } \\
\hline Pac1/kop & $\geq 5000$ & 800 & 30 & $>50,000$ & 3000 & 1200 & 4 \\
\hline \multirow[t]{2}{*}{ Pac2/kop } & $\geq 5000$ & 400 & 30 & $>50,000$ & 3000 & 1200 & 4 \\
\hline & \multicolumn{7}{|c|}{ Indoor Paecilomyces sp. strains } \\
\hline Pec1/skk & $\geq 5000$ & 800 & 16 & $>50,000$ & 3000 & 1200 & 4 \\
\hline \multirow[t]{2}{*}{ Pec1/his } & $\geq 5000$ & 400 & 30 & $>50,000$ & 3000 & 1200 & 30 \\
\hline & & \multicolumn{6}{|c|}{ Indoor Trichoderma longibrachiatum strain } \\
\hline \multirow[t]{2}{*}{ THG } & $\underline{1200}$ & $<50$ & 1 & $>50,000$ & 1500 & 1200 & 16 \\
\hline & \multicolumn{7}{|c|}{ Indoor Trichoderma citrinoviride strain } \\
\hline \multirow[t]{3}{*}{ SJ40 } & 1200 & $<50$ & 2 & $>50,000$ & 1500 & 1200 & 8 \\
\hline & \multicolumn{7}{|c|}{ Strains not able to grow at $37^{\circ} \mathrm{C}$} \\
\hline & \multicolumn{7}{|c|}{ Aspergillus versicolor strains } \\
\hline $\mathrm{SL} / 3$ & 5000 & 100 & 60 & $>50,000$ & 800 & 600 & 16 \\
\hline Gas/226 & 5000 & 100 & 60 & $>50,000$ & 400 & 1200 & 16 \\
\hline
\end{tabular}


Table 4. Cont.

\begin{tabular}{|c|c|c|c|c|c|c|c|}
\hline \multirow{2}{*}{ Strain Code } & \multicolumn{7}{|c|}{$\mathrm{EC}_{50}\left(\mu \mathrm{g} \mathrm{mL}^{-1}\right)$} \\
\hline & Borax & Boracol & РHMB & Genapol-X080 & Phenoxy-ethanol & Chloramine & Triclosan \\
\hline & \multicolumn{7}{|c|}{ Aspergillus westerdijkiae strains } \\
\hline PP2 & 5000 & 100 & 60 & $>50,000$ & 1500 & 600 & 16 \\
\hline PP3 & 5000 & 100 & 60 & $>50,000$ & 1500 & 600 & 16 \\
\hline $\mathrm{AW} / \mathrm{KL}$ & 2500 & 100 & 60 & $>50,000$ & 1500 & 600 & 16 \\
\hline \multicolumn{8}{|c|}{ Indoor Trichoderma atroviride strains } \\
\hline $\mathrm{H} 1 / 226$ & 1200 & 100 & 2 & $>50,000$ & 1500 & 1200 & 16 \\
\hline Ke14 & 1200 & 100 & 4 & $>50,000$ & 1500 & 1200 & 16 \\
\hline KIV10 & 2500 & 100 & 4 & $>50,000$ & 3000 & 2400 & 30 \\
\hline Tri335 & 2500 & 100 & 4 & $>50,000$ & 3000 & 1200 & 30 \\
\hline 14/AM & 1200 & 100 & 4 & $>50,000$ & 3000 & 1200 & 30 \\
\hline Tri7A/SKK & 1200 & 100 & 8 & $>50,000$ & 1500 & 2500 & 16 \\
\hline \multicolumn{8}{|c|}{ Outdoor T. atroviride strains } \\
\hline SZMC 12541 & 1200 & 100 & 2 & $>50,000$ & 1500 & 2500 & 16 \\
\hline SZMC 12474 & 2500 & 100 & 4 & $>50,000$ & 3000 & 2500 & 8 \\
\hline SZMC 207080 & 1200 & 100 & 8 & $>50,000$ & 3000 & 2500 & 8 \\
\hline SZMC 1723 & 1200 & 100 & 8 & $>50,000$ & 1500 & 2500 & 16 \\
\hline SZMC 12516 & 2500 & 200 & 30 & $>50,000$ & 1500 & 2500 & 16 \\
\hline SZMC 12323 & 1200 & 100 & 8 & $>50,000$ & 1500 & 2500 & 30 \\
\hline \multicolumn{8}{|c|}{ Indoor Penicillium sp. strains unable to grow at $37^{\circ} \mathrm{C}$} \\
\hline 35/skk & 5000 & $<50$ & 30 & $>50,000$ & 350 & 600 & ND \\
\hline 26/skk & $>5000$ & $<50$ & 30 & $>50,000$ & 3000 & 600 & 30 \\
\hline $5 /$ skk & 2500 & 100 & 8 & $>50,000$ & 1500 & 600 & 2 \\
\hline $\mathrm{HJ} 2$ & 2500 & 100 & 1 & $>50,000$ & 800 & 1200 & 8 \\
\hline $20 \mathrm{~b} / \mathrm{skk}$ & $>5000$ & $<50$ & 30 & $>50,000$ & 1500 & 600 & 2 \\
\hline Vaip/skk & $>5000$ & $<50$ & 8 & $>50,000$ & 800 & 600 & 4 \\
\hline \multicolumn{8}{|c|}{ Mammalian cell lines (ICT assay) } \\
\hline MNA & 150 & $<50$ & 4 & 25 & 400 & 80 & $4-8$ \\
\hline PK-15 & 600 & $<50$ & 15 & 25 & 1500 & 150 & $8-15$ \\
\hline
\end{tabular}

\section{Discussion}

This study revealed that fluorescence emission and toxic responses in two screening assays of biomass dispersal are useful in rapid screening procedures for tracking the diversity of toxigenic indoor ascomata-producing Chaetomium-like isolates. In addition to the most abundant species Ch. globosum, two other species-Ch. cochliodes and Ch. rectangulare, which have not been previously investigated in buildings in Finland-were found. The blue/green fluorescent (morphotype A in Figure 2) and non-fluorescent (morphotype B in Figure 2) strains exhibiting unbranched ascomatal hair were identified as toxigenic Ch. globosum and Ch. cochliodes, respectively, which produce chaetoglobosin and chaetomin, as the dominant mycotoxins detected. The blue fluorescent isolates (morphotype $\mathrm{C}$ in Figure 2) exhibiting dichotomously branched ascomatal hair and small ascospores were tentatively identified down to the genus level based on their morphology. These strains were isolated from an inlet air filter and possibly came from the outdoor air (Table 1). The yellow fluorescent toxigenic isolates (morphotype D in Figure 1) exhibiting dichotomously branched ascomatal hair and large ascospores were identified as $C h$. rectangulare, and its toxin production, as well as the biological activity of the produced toxins and the possible correlation of these toxins to piglet mortality [34], will be investigated in a separate paper.

The indoor-isolated Ch. globosum and Ch. cochliodes strains were shown to produce mycotoxins, including chaetoglobosin, chaetoviridin A and C, chaetomugilin D and chaetomin, on laboratory media and building materials, suggesting that mycotoxin production is not species-specific $[2,9,28,45]$. In our study, there is a clear difference in mycotoxin production between Ch. globosum and Ch. cochliodes. For instance, the amount of chaetomin in Ch. cochliodes extracts was one-fourth 
that of chaetoglobosin in the Ch. globosum extracts. However, in the ICP assay, the $\mathrm{EC}_{50}$ concentrations of the chaetomin-containing extracts were 100 times lower compared with that of the chaetoglobosin-containing extracts. By contrast, their $\mathrm{EC}_{50}$ concentrations in the BSMI assay were similar. This result indicates that the chaetomin-containing extracts were more toxic to the cell lines used or that chaetoglobosin was more susceptible to inactivation during the extraction process; for instance, chaetoglobosin could be inactivated by the heat treatment and ethanol extraction needed for ascospore inactivation. For chaetomin, its sperm motility-inhibiting effect may be explained in terms of mitochondrial toxicity. Chaetomin is known to induce cell apoptosis by disrupting the mitochondrial function and by promoting calcium overload [46]. For chaetoglobosin, its sperm motility-inhibiting effect and cytostatic effect could be very likely explained by its glucose transport-inhibiting activity $[23,33]$. This result indicates that the chaetoglobosin did not target mitochondria. Thus, energy depletion caused by inhibition of sugar transport may be monitored as a sublethal toxicity in boar sperm [32]. The chaetoglobosin-producing Ch. globosum strains apparently excrete chaetoglobosin in liquid vesicles (Figure 5 and Table 3).

Although the number of indoor isolates in this study was limited, the results indicate that the chaetoglobosin-producing $\mathrm{Ch}$. globosum-like strains are the most common but not the only ascomata-producing fungi in the investigated buildings in Finland. In addition, the most commonly isolated indoor Chaetomium species worldwide is Ch. globosum [2,3]. To the best of our knowledge, chaetomin-producing indoor $\mathrm{Ch}$. cochliodes or $\mathrm{Ch}$. rectangulare isolates have not yet been reported in Finland.

Ch. globosum was shown to cause changes in the structure and porosity of plywood and concrete, allowing them to penetrate building materials in search for nutrients. Over time, building materials will become more fragile, resulting in construction issues $[5,47]$. Such a characteristic is possibly the reason fungal growth is difficult to eradicate. The results demonstrate the variability among indoor fungal species and genera in terms of biocide/chemical resistance. All of the tested chaetoglobosin-producing strains but none of the tested Aspergillus, Trichoderma, Paecilomyces or Penicillium strains were sensitive to Genapol-X080. It is tempting to speculate about a correlation between chaetoglobosin production and Genapol-X080 sensitivity. Interestingly, no difference in resistance pattern was observed between the indoor and outdoor strains of T. atroviride. Biocide resistance seems to be a species-specific characteristic. The indoor use of biocides and chemicals may influence the proliferation and species diversity of the indoor microbiota.

\section{Conclusions}

The tested blue/green fluorescent Ch. globosum strains isolated from eight buildings exhibited a uniform mycotoxin profile that was dominated by chaetoglobosin. The isolates exhibited a uniform sublethal toxicological profile, which is attributed to energy depletion. The isolates displayed a uniform resistance profile towards indoor detergents and biocides, but a profile which differed from that of other species that are sensitive to Genapol-X080. The two non-fluorescent, chaetomin-producing Ch. cochliodes and the two yellow fluorescent $C h$. rectangulare strains differed from the tested $\mathrm{Ch}$. globosum strain in all characteristics. This diversity based on fluorescence and biocide/Genapol-X080 resistance was confirmed by toxicity and metabolite profiling and by the tef $1 \alpha$ sequence-based identification. Thus, fluorescence, biocide/Genapol-X080 resistance, and toxicity screening are potentially useful in the preliminary diversity tracking of mycotoxinogenic isolates belonging to the Ch. globosum complex.

\section{Materials and Methods}

\subsection{Experimental Design}

New methods for tracking the diversity of toxigenic ascomata-producing colonies cultivated from indoor dusts were developed. These methods were employed to detect and characterize the indoor Chaetomium strains. Settled dust and inlet air filters were collected from urban and rural buildings 
associated with severe health problems in Finland. Biomass suspensions of mold colonies from the primary cultivation plates were screened using two complementary rapid toxicity tests. The colonies found to be toxic in the two assays were examined under a light microscope for ascomata formation. The biomass suspensions prepared from these colonies were inspected for fluorescence emission.

The toxigenic ascomata-producing colonies from the primary isolation plates were streaked into pure, single-spored cultures and classified into four morphotypes denoted as A-D based on the morphology of their ascomata and on their fluorescence emission. Representatives of morphotypes A-C from different buildings were identified down to the species level. The strains exhibiting morphotypes A and B and belonging to the genus Chaetomium were investigated for mycotoxin production. The mycotoxins in the extracted biomass were analyzed and identified with HPLC-MS. The biological effects and targets of the toxins were elucidated in a set of four bioassays and then compared with selected pure mycotoxins from selected reference indoor fungi. The sensitivity of the Chaetomium strains to biocides and to the wetting agent Genapol-080 was compared with that of selected representatives of indoor and outdoor fungal species and genera.

\subsection{Cultivation of Mold Colonies}

The methods used for cultivating the mold colonies on malt extract agar ( $15 \mathrm{~g}$ malt extract from Sharlab, Spain, and $12 \mathrm{~g}$ of agar from Amresco, Solon $\mathrm{OH}$, USA, in $500 \mathrm{~mL}$ of $\mathrm{H}_{2} \mathrm{O}$ ) were described previously $[17,18]$. After three weeks of incubation, the colonies on the primary isolation plates (not yet single spored) were numbered and screened for toxicity [17,18].

\subsection{Rapid Screening Tests Using Ex Vivo and In Vitro Assays}

The toxicity tests measured: (a) the toxins affecting the cellular energy metabolism, the mitochondria and ion homeostasis based on the inhibition of the motility of boar spermatozoa (BSMI) $[13,15,16,48]$; and (b) the toxins affecting macromolecular synthesis and cytostatic activity based on the inhibition of the proliferation of the somatic cell line PK-15 (ICP) [49]. The screening tests that were applied directly to the primary sampling plates and designed for mycotoxinogenic indoor molds were described previously [34]. In this study, the procedure of the test was briefly as follows: $10-20 \mathrm{mg}$ of colony biomass were suspended in $200 \mu \mathrm{L}$ of ethanol and heated in a water bath to $55-60{ }^{\circ} \mathrm{C}$ for $10 \mathrm{~min}$. In the ex vivo test, the rapid BSMI assay red after $30 \mathrm{~min}$ of exposure, $200 \mu \mathrm{L}$ of extended boar semen were exposed to $5 \mu \mathrm{L}$ of biomass suspension. In the slower version of the test, when 1 and 3 days of exposure were used, $2 \mathrm{~mL}$ of extended boar semen were exposed to $10 \mu \mathrm{L}$ of biomass suspension. The sperm cells were exposed at $24^{\circ} \mathrm{C}$. A colony was considered very toxic in the BSMI assay when $\leq 2.5 \mathrm{vol} \%$ of its biomass suspension inhibited the boar sperm motility after $30 \mathrm{~min}$ to 1 day exposure and slightly toxic if the motility inhibition occurred after 3 days of exposure. A colony was considered toxic in the in vitro ICP assay when $\leq 5 \mathrm{vol} \%$ inhibition of cell proliferation (ICP) assays the proliferation of the porcine kidney (PK-15) cells after 2 days of exposure, respectively.

\subsection{Toxicity Assays for Ethanol-Soluble Dry Substances Extracted from a Plate-Grown Fungal Biomass and Pure Mycotoxins}

The plate-grown biomass of the fungal pure cultures $(100-300 \mathrm{mg}$ ) was extracted with ethanol as described earlier [31]. The toxicity assays, namely BSMI assay after exposure for $30 \mathrm{~min}$ (rapid inhibition) and for one day (slow inhibition), SMID assay and ICP assay, were all described previously $[15,16]$. The toxicity assays involving the ethanol extracts obtained from pure fungal cultures were performed using porcine cells (sperms and somatic cell lines) as indicators according to methods described before $[13,18,41,50]$. The calculation of $\mathrm{EC}_{50}$ - the half maximal effective concentration for the ethanol-dry substances and pure mycotoxins in the BSMI, SMID and ICP assays-were described previously $[15,18]$.

The procedure for the $\mathrm{BSMI}_{\mathrm{R}}$ assay measuring sublethal toxicity as motility inhibition, i.e., inability to respond to induction of motility in resting sperm cells is described below: The ethanol solutions 
$(0.5-10 \mu \mathrm{L})$ were dispensed in $2000 \mu \mathrm{L}$ of extended boar semen (Figen Ltd., Tuomikylä, Finland, density of $27 \times 10^{6}$ sperms $\mathrm{mL}^{-1}$ ) incubated at $24^{\circ} \mathrm{C}$, and motility of the sperms was inspected in the phase-contrast microscope (400× magnification) with a heated stage, (Olympus CKX41, Tokyo, Japan; magnification $400 \times$ ) and an image recording software (Cellsense ${ }^{\circledR}$ standard version 11.0.06, Olympus Soft Imaging Solutions GmbH, Münster, Germany, 2012) as described previously [34]. Briefly, the $\mathrm{EC}_{50}$ concentration for motility inhibition was concluded as the toxin concentration closest to that provoking a $>50 \%$ decrease in the number of sperm cells exhibiting rapid tail beating, compared with the sperm cells in the solvent control. The $\mathrm{EC}_{50}$ was calculated from the equation of the straight line between $\mathrm{EC}_{50-40}$ and $\mathrm{EC}_{80-90}: \mathrm{Y}=-\Delta \mathrm{Y} / \Delta \mathrm{X} \times \mathrm{X}+\mathrm{C}$ where $\mathrm{Y}$ is the motility closest to $50 \%$ of the motility of the solvent control, $\mathrm{X}$ is the $\mathrm{EC}_{50}$ concentration and $\mathrm{C}$ is a constant between $100 \%$ and $60 \%$. All tests were run in triplicates and differences between replicate tests were within one dilution step (2-fold). The sperm assays were calibrated with triclosan and valinomycin.

The boar sperm motility inhibition assay with motile spermatozoa $\left(\mathrm{BSMI}_{\mathrm{M}}\right)$ measuring inability to maintain induced motility was performed as follows: Motile sperm cells were exposed to dilutions of the biomass extracts and exudates at $37^{\circ} \mathrm{C}$ for $20 \mathrm{~min}$. Aliquots of $200 \mu \mathrm{L}$ of extended boar semen were exposed to $0.5,1$ and $2 \mu \mathrm{L}$ of ethanol-soluble compounds from ten-fold dilutions of biomass extracts or exudates. Estimation of the ratio of motile spermatozoa compared to the control and calculation of $\mathrm{EC}_{50}$ was done as in the BSMIR assay described above.

Lethal toxicity was measured as sperm membrane integrity disruption assay with motile spermatozoa $\left(\mathrm{SMID}_{\mathrm{M}}\right)$, was assessed by staining with PI as described [18] with modifications. Aliquots of $50 \mu \mathrm{L}$ PBS were pipetted into a microtiter plate. Ethanol-soluble compounds from biomasses $(50 \mu \mathrm{L})$ of fungal strains were serially diluted to $10^{9}$, and extended boar cell aliquots $(150 \mu \mathrm{L})$ were added to the wells. The possible autofluorescence of the toxins was excluded. PBS was used as a blank reagent. Three parallel dilutions were performed for each sample. Frozen-thawed semen only exposed to ethanol was used as a positive control (100\% mortality) representing the maximal fluorescence emitted by the cells permeable to PI. Sperm cells only exposed to ethanol were used as a negative control (viable cells). The microtiter plate was pre-incubated for $2 \mathrm{~h}$ at $37^{\circ} \mathrm{C}$ on an orbital shaker (Innova 5000 New Brunswick Scientific, Enfield, CT, USA) at $160 \mathrm{rpm}$. A volume of $100 \mu \mathrm{L}$ PI solution $\left(10 \mu \mathrm{g} \mathrm{mL}^{-1}\right)$ was added to each well of the microtiter plate. The plate was incubated for $15 \mathrm{~min}$ at $37^{\circ} \mathrm{C}$ in the dark. Fluorescence was measured with a microplate reader (Fluoroskan Ascent, Thermo Scientific, Vantaa, Finland) at excitation and emission wavelengths of 544 and $590 \mathrm{~nm}$, respectively.

The test for mitochondrial damage as indicated by accelerated glucose consumption and extracellular acidosis was described earlier [24,51,52]. The PK-15 cells were grown in 8-well flat-bottom chamber glass slides, seeded to a density of $4 \times 10^{4}$ cells $\mathrm{mL}^{-1}$, in the respective medium for $48 \mathrm{~h}$. The twofold serially diluted test substances or the vehicle only was dispensed into the wells. The glucose content of the wells was measured by using a glucose meter (Precision Xceed; Abbott Diabetes Care Ltd., Berkshire, United Kingdom). In wells that received nothing or the vehicle only, the glucose concentration decreased from an initial concentration $(0 \mathrm{~h})$ of 12 to $6 \mathrm{mM}(24 \mathrm{~h})$, but the $\mathrm{pH}$ remained as $\mathrm{pH}$ of 7.2. A glucose concentration after $24 \mathrm{~h}$ of $\leq 3 \mathrm{mM}$ indicated excessive glucose consumption. Prior to the measurement of the $\mathrm{pH}$, the chamber slides were transferred into ambient air for $1 \mathrm{~h}$ to allow $\mathrm{CO}_{2}$ to evaporate. A pH drop of 0.5 units in the toxin-exposed well compared to the vehicle only was considered proof of acidosis. Mitochondrial depolarization ( $\triangle \Psi \mathrm{m}$ assay) was read by a fluorescence microscope after $26 \mathrm{~h}$ of exposure to the toxicants from the monolayers double stained with the membrane potential-responsive fluorogenic dye JC- 1 and with propidium iodide to assess the relaxing of the plasma membrane permeability barrier, similar to what was reported previously for sperm cells (27).

\subsection{Fluorescence Microscopy of Resting Spermatozoa Exposed in the $S M I D_{R}$ and the $\Delta \Psi m$ Assays}

The boar sperm cells exposed for 2 days to commercial chaetoglobosin A and the crude extract of MTAV35 and MTAV37 were double-stained with the viability stains PI + calcein-AM, the SMID 
assay, as described earlier [53]. The staining protocol was as follows: $200 \mu \mathrm{L}$ of extended boar semen containing $27 \times 10^{6}$ sperm cells $\mathrm{mL}^{-1}$ was mixed with $200 \mu \mathrm{L}$ PBS containing $3 \mu \mathrm{g} \mathrm{mL} \mathrm{m}^{-1}$ calcein-AM and $10 \mu \mathrm{g} \mathrm{mL} \mathrm{m}^{-1} \mathrm{PI}$. The $\Delta \Psi \mathrm{m}$ assay monitored the mitochondrial membrane potential changes $(\Delta \Psi \mathrm{m})$ by staining with the lipophilic potentiometric dye JC-1 as described by Mikkola et al. (2015). For the staining with JC-1 $\left(35 \mu \mathrm{g} \mathrm{mL}{ }^{-1}\right), 200 \mu \mathrm{L}$ of the sperm cells were shaken and incubated at $37^{\circ} \mathrm{C}$ for $5 \mathrm{~min}$. After staining, the cells exposed in the $\mathrm{SMID}_{\mathrm{R}}$ and the $\Delta \Psi \mathrm{m}$ assays were inspected with fluorescence microscope using 400× magnification (Nikon Eclipse E600, Nikon Corporation, Tokyo Japan) with filters BP 450-490 nm/LP 520. The calcein-AM-stained cells with intact plasma membranes produced green fluorescence, whereas the PI-dyed cells with damaged plasma membranes produced red fluorescence. In JC-1 stained sperm cells, mitochondria with high membrane potential emitted yellow fluorescence, whereas depolarized mitochondria fluoresced green.

The $\mathrm{EC}_{50}$ concentration in these microscopic assays was defined as the lowest concentration where the ratio of cells similar to those in the solvent control was less than $50 \%$. This $\mathrm{EC}_{50}$ fitted between $\mathrm{EC}_{90}$ and $\mathrm{EC}_{10}$ observed in the microscope calculating ca. 100-120 sperm cells from three microscopic fields. The maximal difference between four parallel tests in each of the two methods was one dilution step. The assays were calibrated with triclosan.

\subsection{Identification of the Fungal Strains}

The isolates were initially identified down to the genus level based on colony morphology on MEA, on conidiophore morphology as seen under a light microscope, and on conidial size [54].

The Ch. globosum MH52, HAS5, 2b/26, C22/LM, RUK10 and MO9 strains; the Ch. cochliodes OT7 and $\mathrm{OT} 7 \mathrm{~b}$ strains; and the $\mathrm{Ch}$. rectangulare $\mathrm{MO} 13$ and $\mathrm{MO} 15$ strains were identified in the present study based on the amplification of a fragment of the translation elongation factor 1 alpha (tef $1 \alpha)$ gene as described earlier [55], (GenBank Accession numbers: MT498101-MT498110).

The reference strains A. westerdijkiae PP2 and PP3, A. versicolor SL/3 and GAS/226, Ch. globosum MTAV35 and Paecilomyces variotii Paec 1/kop and Paec 2/kop were identified at DSMZ (Deutsche Sammlung von Mikroorganismen und Zellkulturen) between 2004 and 2008. The T. atroviride strains Ke14 [6], KIV10, Tri335, 14/AM and H1/226 as well as the strains T. citrinoviride SJ40 [25] and T. longibrachiatum HAMBI 3643 (=SzMC Thg) [56] were identified previously based on internal transcribed spacer (ITS) and/or tef1 $\alpha$ sequence analysis. The identification of $A$. calidoustus MH4 based on ITS was described earlier [34].

The outdoor T. atroviride strains were obtained from the Szeged Microbiology Collection (www. szmc.hu, University of Szeged, Hungary).

\subsection{HPLC-MS Analysis and Identification of Mycotoxins in the Fungal Extracts}

The biomass ( $400 \pm 50 \mathrm{mg}$ ) of the selected Ch. globosum and Ch. cochliodes strains was harvested from a malt extract agar (MEA) plate incubated at $24^{\circ} \mathrm{C}$ for 14 days. The fungal toxins were extracted with ethanol from the collected biomass, and the ethanolic extract was analyzed by high-performance liquid chromatography-mass spectrometry (HPLC-MS). The HPLC-electrospray ionization ion trap mass spectrometry analysis (ESI-IT-MS) was performed using an MSD-Trap-XCT plus ion trap mass spectrometer equipped with an Agilent ESI source and Agilent 1100 series LC (Agilent Technologies, Wilmington, Del., USA) in positive mode with the mass range of $m / z$ 50-2000. ESI source parameters used for analysis were: nebulizer gas pressure, 35 psi; drying gas flow rate, $8 \mathrm{~L} \mathrm{~min}^{-1}$; drying gas temperature, $350^{\circ} \mathrm{C}$; and a capillary voltage of $5000 \mathrm{~V}$. The column used was a SunFire C18, $2.1 \times 50 \mathrm{~mm}$, $2.5 \mu \mathrm{m}$ (Waters, Milford, MA, USA). Separation of compounds from the ethanol extract of biomasses of Ch. globosum and Ch. cochliodes strains was done using an isocratic method of solution $\mathrm{A}: \mathrm{H}_{2} \mathrm{O}$ with $0 \cdot 1 \%(\mathrm{v} / \mathrm{v})$ formic acid and B: methanol in a ratio of $40 / 60(\mathrm{v} / \mathrm{v})$ for $15 \mathrm{~min}$ and gradient of $100 \%$ B for $50 \mathrm{~min}$ at a flow rate of $0.2 \mathrm{~mL} \mathrm{~min}^{-1}$. Identification and quantification of compounds was done by HPLC-UV-MS and MS/MS analysis. 


\subsection{Methods for Testing the Toxicity of Biocides and Genapol-X080 towards the Fungi}

The toxicity of biocides and chemicals towards the indoor Chaetomium-like isolates and the reference indoor strains of the genera Aspergillus, Paecilomyces, Penicillium and Trichoderma was assessed in parallel with the six parameters presented in the Supplementary Materials: (1) germ tube assay (Figure S3); (2) estimation of turbidity (Figure S4); (3) visual emission of fluorescence (excitation at $360 \mathrm{~nm}$ ); (4) visual resporulation of conidia; (5) inhibition of glucose consumption [51]; and (6) resazurin reduction. All assays were performed in malt extract broth $\left(12 \mathrm{~g} \mathrm{~L}^{-1}\right.$ malt extract, $7.2 \mu \mathrm{mol} \mathrm{mL}^{-1}$ glucose, pH 5.5; Scharlab, Barcelona, Spain) in 96-well microtiter plates as described for the ICP assay.

The assays measuring inhibition of germination of conidia were done with spore suspensions of $1-2 \times 10^{6}$ fungal spores $\mathrm{mL}-{ }^{1}$. The tests were performed in malt extract broth (Oxoid, Hampshire United Kingdom) $12 \mathrm{~g}$ in $1 \mathrm{~L}$, pH 5.5, glucose $7.1 \mathrm{mmol} \mathrm{L}^{-1}$, and performed on microtiter plates as described by Bencsik et al. [3] for the ICP assay. The germ tube germination is visualized in Figure S3, and the tests estimating turbidity and emission of fluorescence provoked by the germinated and metabolically active conidia and C. globosum ascospores are visualized in Figures S4 and S5. Examples of the tests estimating fluorescence emission, turbidity and re-sporulation of conidia and ascospores are compared in Figure S5. The difference of the endpoints measured with the different assays was between $38 \%$ and $<28.5 \%$. The resazurin reduction assays (Figure S6) were performed as described for the ICP assay, except that the microtiter plates were visually inspected for the change of the blue/violet color of resazurin (indicating inhibition of germination of the exposed conidia) to the colorless dihydroresorufin (indicating metabolic activity and germination of the exposed conidia).

The formation of germ tubes was inspected by a phase-contrast microscope (Olympus CKX41, Tokyo, Japan; magnification $400 \times$ ) and an image recording software (Cellsense ${ }^{\circledR}$ standard version 11.0.06, Olympus Soft Imaging Solutions GmbH, Münster, Germany, 2012) after 1 and 2 days of incubation at $28^{\circ} \mathrm{C}$. The $\mathrm{EC}_{50}$ corresponded to the inhibition of $50 \%$ (estimated as the concentration between $\mathrm{EC}_{0}$ and $\mathrm{EC}_{100}$ ) of the conidia compared to the ethanol control (the growth medium containing $1 \%$ of ethanol). The tests were run in triplicate and calibrated with triclosan (CAS: 3380-34-5; Sigma Chemical Co., St. Louis, MO, USA) giving a mean SD of $\pm<20 \%$.

\subsection{Reagents and Supplies}

The continuous cell line PK-15 (porcine kidney cells) and a malignant cell line (MNA cell line) provided by EVIRA (Helsinki, Finland) were used in the ICP assay. 5,5',6,6' -tetrachloro-1,1',3,3' -tetraethyl-benzimidazolylcarbocyanine iodide (JC-1, 3520-43-2), PI (25535-16-4) and calcein-AM (148504-34-1) were obtained from Invitrogen (Carlsbad, CA, USA). Alamethicin A4665 (T. arundinaceum) (CAS 27061-78-5), a mixture of alamethicin F50 peptaibols (MW 1962, 1976, 1976 and 1990), chaetoglobosin A (CAS 50335-03-0), sterigmatocystin (CAS 10048-13-5) and ochratoxin A (CAS 303-47-9) were obtained from Sigma-Aldrich (St. Louis, MO, USA). Malt extract and tryptic soy agar were obtained from Scharlab (Barcelona, Spain). The other chemicals were of analytical grade and were purchased from local suppliers. The biocides and the wetting agent Genapol-080 were purchased from Sigma-Aldrich Finland. The fungicide Boracol 10Rh was obtained from a local supplier. The selected biocides were Borax (600 $\mathrm{g} \mathrm{mL}^{-1}$; sodium tetraborate, CAS: 1330-43-4), Boracol 10Rh containing disodium octaborate tetrahydrate (CAS: 12280-03-04) and didecyldimethylammonium chloride [CAS: 7173-51-5]), PHMB (CAS: 27083-27-8), phenoxyethanol (CAS: 122-99-6), chloramine, triclosan (5-Chloro-2-(2,4-dichlorophenoxy)phenol, CAS: 3380-34-5) and the wetting agent Genapol X-080 (CAS: 9043-30-5). Genapol X-080 and the biocides were purchased from Sigma-Aldrich, except for Boracol 10Rh, which was purchased from a local supplier.

Supplementary Materials: The following are available online at http://www.mdpi.com/2072-6651/12/7/443/s1, Figure S1: The MS and MS/MS spectra of the compounds of the Ch. globosum RUK10 and Ch. cochliodes OT7; Figure S2: UV-spectra of the compounds of the Ch. globosum strains MTAV35, HAS5, RUK10 and ABCD and Ch. cochliodes strains OT7 and OT7b; Figure S3: Germ tube test performed with Aspergillus westerdijkiae strain PP2 exposed for $48 \mathrm{~h}$ at $28^{\circ} \mathrm{C}$ to Triclosan; Figure S4: Toxicity of selected chemicals visible as lack of turbidity of 
two-fold dilutions from left to right after $10 \mathrm{~d}$ of incubation; Figure S5: Resistance to biocides and Genapol visible as fluorescence emission (upper row), turbidimetry (middle row) and resporulation (bottom row); Figure S6: Resistance of biocides and Genapol to Trichoderma atroviride strains estimated as resazurin reduction (Panels A and $\mathrm{C}$ ) and resporulation (B and D).

Author Contributions: Conceptualization, J.M.S. and M.A.A.; Data curation, J.M.S., O.K., R.M., L.K. and M.A.A.; Formal analysis, J.M.S., O.K., R.M. and M.A.A.; Funding acquisition, J.K. and H.S.; Investigation, J.M.S., O.K., R.M. and M.A.A.; Methodology, J.M.S., R.M. and M.A.A.; Project administration, J.K. and H.S.; Resources, M.A.A.; Supervision, J.K. and H.S.; Validation, O.K., R.M., L.K. and M.A.A.; Visualization, J.M.S. and M.A.A.; Writing-original draft, J.M.S., O.K., R.M., L.K. and M.A.A.; and Writing-review and editing, J.M.S., O.K., R.M., L.K., M.A.A. and H.S. All authors have read and agreed to the published version of the manuscript.

Funding: This research was funded by the Academy of Finland (TOXICPM grant number 289161) and the Finnish Work Environmental Fund (grant number 117101). L.K. is grantee of the János Bolyai (Hungarian Academy of Science) and Bolyai Plus (New National Excellence Programme, Ministry of Human Resources, Hungary) research scholarships.

Acknowledgments: The authors warmly thank Maria Hautaniemi of the Finnish Food Safety Authority (EVIRA) for providing us the porcine kidney cell line PK-15.

Conflicts of Interest: The authors declare no conflict of interest. The funders had no role in the design of the study; in the collection, analyses, or interpretation of data; in the writing of the manuscript, or in the decision to publish the result.

\section{References}

1. Millner, P.D. Radial growth responses to temperature by 58 Chaetomium species, and some taxonomic relationships. Mycologia 1977, 69, 492-502. [CrossRef]

2. Wang, X.W.; Houbraken, J.; Groenewald, J.Z.; Meijer, M.; Andersen, B.; Nielsen, K.F.; Crous, P.W.; Samson, R.A. Diversity and taxonomy of Chaetomium and Chaetomium-like fungi from indoor environments. Stud. Mycol. 2016, 84, 145-224. [CrossRef]

3. Wang, X.W.; Lombard, L.; Groenewald, J.Z.; Li, J.; Videira, S.; Samson, R.; Liu, X.; Crous, P.W. Phylogenetic reassessment of the Chaetomium globosum species complex. Persoonia 2016, 36, 83-183. [CrossRef] [PubMed]

4. Andersen, B.; Trane-Niessen, A. Evaluation of media for detection of Stachybotrys and Chaetomium species associated with water-damaged buildings. Int. Biodeterior. Biodegrad. 2000, 46, 111-116. [CrossRef]

5. Andersen, B.; Frisvad, J.C.; Søndergaard, I.; Rasmussen, S.; Larsen, L. Associations between fungal species and water-damaged building materials. Appl. Environ. Microbiol. 2011, 77, 4180-4188. [CrossRef]

6. Castagnoli, E.; Andersson, M.A.; Mikkola, R.; Kredics, L.; Marik, T.; Kurnitski, J.; Salonen, H. Indoor Chaetomium-like Isolates: Resistance to Chemicals, Fluorescence and Mycotoxin Production. In Proceedings of the Sisäilmastoseminaari 2017, Helsinki, Finland, 15 March 2017; Säteri, J., Ahola, M., Eds.; Sisäilmayhdistys Ry: Juva, Finland, 2017; Volume 35, pp. 227-232.

7. Korpi, A.; Pasanen, A.-L.; Viitanen, H. Volatile metabolites of Serpula lacrymans, Coniophora puteana, Poria placenta, Stachybotrys chartarum and Chaetomium globosum. Build. Environ. 1999, 34, 205-211. [CrossRef]

8. Täubel, M.; Karvonen, A.M.; Reponen, T.; Hyvärinen, A.; Vesper, S.; Pekkanena, J. Application of the environmental relative moldiness index in Finland. Appl. Environ. Microbiol. 2016, 82, 578-584. [CrossRef] [PubMed]

9. Došen, I.; Nielsen, K.F.; Clausen, G.; Andersen, B. Potentially harmful secondary metabolites produced by indoor Chaetomium species on artificially and naturally contaminated building materials. Indoor Air 2017, 1, 34-46. [CrossRef]

10. Bills, G.F.; Gloer, J.B. Biologically active secondary metabolites from the fungi. Microbiol. Spectr. 2016, 4. [CrossRef]

11. Gathercole, P.S.; Thiel, P.G.; Hofmeyer, J.H. Inhibition of pyruvate dehydrogenase complex by moniliformin. Biochem. J. 1986, 233, 719-723. [CrossRef]

12. Andersson, M.A.; Nikulin, M.; Köljalg, U.; Andersson, M.C.; Rainey, F.; Reijula, K.; Hintikka, E.L.; Salkinoja-Salonen, M. Bacteria, molds, and toxins in water-damaged building materials. Appl. Environ. Microbiol. 1997, 63, 387-393. [CrossRef]

13. Andersson, M.A.; Mikkola, R.; Raulio, M.; Kredics, L.; Maijala, P.; Salkinoja-Salonen, M.S. Acrebol, a novel toxic peptaibol produced by an Acremonium exuviarum indoor isolate. J. Appl. Microbiol. 2009, 106, 909-923. [CrossRef] [PubMed] 
14. Kruglov, A.G.; Andersson, M.A.; Mikkola, R.; Roivainen, M.; Kredics, L.; Saris, N.-E.; Salkinoja-Salonen, M.S. Novel mycotoxin from Acremonium exuviarum is a powerful inhibitor of the mitochondrial respiratory chaincomplex III. Chem. Res. Toxicol. 2009, 9, 565-573. [CrossRef]

15. Castagnoli, E.; Marik, T.; Mikkola, R.; Kredics, L.; Andersson, M.A.; Salonen, H.; Kurnitski, J. Indoor Trichoderma strains emitting peptaibols in guttation droplets. J. Appl. Microbiol. 2018, 125, 1408-1422. [CrossRef]

16. Castagnoli, E.; Salo, J.; Toivonen, M.S.; Marik, T.; Mikkola, R.; Kredics, L.; Vicente-Carrillo, A.; Nagy, S.; Andersson, M.T.; Andersson, M.A.; et al. An evaluation of boar spermatozoa as a biosensor for the detection of sublethal and lethal toxicity. Toxins 2018, 10, 463. [CrossRef]

17. Salo, M.J.; Marik, T.; Mikkola, R.; Andersson, M.A.; Kredics, L.; Salonen, H.; Kurnitski, J. Penicillium expansum strain isolated from indoor building material was able to grow on gypsum board and emitted guttation droplets containing chaetoglobosins and communesins A., B and D. J. Appl. Microbiol. 2019, 127, 1135-1147. [CrossRef]

18. Salo, M.J.; Marik, T.; Bencsik, O.; Mikkola, R.; Kredics, L.; Szekeres, A.; Andersson, M.A.; Salonen, H.; Kurnitski, J. Screening mold colonies by using two toxicity assays revealed indoor strains of Aspergillus calidoustus producing ophiobolins G and K. Toxins 2019, 11, 683. [CrossRef] [PubMed]

19. Corrier, D. Mycotoxicosis: Mechanisms of immunosuppression. Vet. Immunol. Immunopathol. 1991, 30, 73-87. [CrossRef]

20. Garbacz, M.; Malec, A.; Duda-Saternus, S.; Suchorab, Z.; Guz, Ł.; Łagód, G. Methods for early detection of microbiological infestation of buildings based on gas sensor technologies. Chemosensors 2020, 8, 7. [CrossRef]

21. European Agency for Safety and Health at Work. Expert Forecast on Emerging Biological Risks Related to Occupational Safety and Health. European Risk Observatory Report. 2007. Available online: https://osha.europa.eu/en/publications/report-expert-forecast-emerging-biological-risksrelatedoccupational-safety-and-health (accessed on 20 November 2019).

22. Liew, W.-P.-P.; Mohd-Redzwan, S. Mycotoxin: Its impact on gut health and microbiota. Front. Cell. Infect. Microbiol. 2018, 8. [CrossRef] [PubMed]

23. Piecková, E. In vitro toxicity of indoor Chaetomium Kunze ex Fr. Ann. Agric. Environ. Med. 2003, 10, 9-14. [PubMed]

24. Piecková, E.; Kunová, Z. Indoor fungi and their ciliostatic metabolites. Ann. Agric. Environ. Med. 2002, 9, 59-63.

25. Piecková, E.; Wilkins, K. Airway toxicity of house dust and its fungal composition. Ann. Agric. Environ. Med. 2004, 11, 67-73.

26. Nikulin, M.; Reijula, K.; Jarvis, B.B.; Hintikka, E.L. Experimental lung mycotoxicosis in mice induced by Stachybotrys atra. Int. J. Exp. Pathol. 1996, 77, 213-218. [CrossRef] [PubMed]

27. Nikulin, M.; Reijula, K.; Jarvis, B.B.; Veijalainen, P.; Hintikka, E.L. Effects of intranasal exposure to spores of Stachybotrys atra in mice. Fundam. Appl. Toxicol. 1997, 35, 182-188. [CrossRef] [PubMed]

28. Rand, T.G.; Chang, C.T.; McMullin, D.R.; Miller, J.D. Inflammation-associated gene expression in RAW 264.7 macrophages induced by toxins from fungi common on damp building materials. Toxicol. In Vitro 2017, 43, 16-20. [CrossRef] [PubMed]

29. Fogle, M.R.; Douglas, D.R.; Jumper, C.A.; Straus, D.C. Growth and mycotoxin production by Chaetomium globosum. Mycopathologia 2007, 164, 49-56. [CrossRef] [PubMed]

30. Caillaud, D.; Leynaert, B.; Keirsbulck, M.; Nadif, R. Indoor mould exposure, asthma and rhinitis: Findings from systematic reviews and recent longitudinal studies-A review. Eur. Respir. Rev. 2018, 27, 170-199. [CrossRef]

31. Shi, D.; Lu, G.; Mei, H.; de Hoog, G.; Zheng, H.; Liang, G.; Shen, Y.; Li, T.; Liu, W. Onychomycosis due to Chaetomium globosum with yellowish black discoloration and periungual inflammation. Med. Mycol. Case Rep. 2016, 13, 12-16. [CrossRef]

32. Ahmed, S.; Khan, Z.; Wang, X.; Moussa, T.; Al-Zahrani, H.; Almaghrabi, O.; Sutton, D.A.; Ahmad, S.; Groenewald, J.; Alastruey-Izquierdo, A.; et al. Chaetomium-like fungi causing opportunistic infections in humans: A possible role for extremotolerance. Fungal Divers. 2016, 76, 11-26. [CrossRef]

33. Lesire, V.; Hazouard, E.; Dequin, F.-E.; Delain, M.; Thérizol-Ferly, M.; Legras, A. Possible role of Chaetomium globosum in infection after autologous bone marrow transplantation. Intensive Care Med. 1999, 25, 124-125. [CrossRef] 
34. Mikkola, R.; Andersson, M.A.; Grigoriev, P.; Heinonen, M.; Salkinoja-Salonen, M.S. The toxic mode of action of cyclic lipodepsipeptide fusaricidins, produced by Paenibacillus polymyxa, toward mammalian cells. J. Appl. Microbiol. 2017, 123, 436-449. [CrossRef]

35. Xu, G.B.; Li, L.M.; Fang, D.M.; Li, G.Y.; Zhang, G.L.; Wu, Z.J. Electrospray ionization tandem mass spectrometry of chaetoglobosins. Rapid Commun. Mass Spectrom. 2012, 26, 2115-2122. [CrossRef] [PubMed]

36. Walsh, J.P.; Renaud, J.B.; Hoogstra, S.; McMullin, D.R.; Ibrahim, A.; Visagie, C.M.; Anney, J.B.; Yeung, K.K.; Sumarah, M.W. Diagnostic fragmentation filtering for the discovery of new chaetoglobosins and cytochalasins. Rapid Commun. Mass Spectrom. 2019, 33, 133-139. [CrossRef] [PubMed]

37. Nielsen, K.F.; Smedsgaard, J. Fungal metabolite screening: Database of 474 mycotoxins and fungal metabolites for dereplication by standardised liquid chromatography-UV-mass spectrometry methodology. J. Chromatogr. A 2003, 100, 111-136. [CrossRef]

38. Larsen, T.O.; Smedsgaard, J.; Fog Nielsen, K.; Hansen, M.E.; Frisvad, J.C. Phenotypic taxonomy and metabolite profiling in microbial drug discovery. Nat. Prod. Rep. 2005, 22, 672-695. [CrossRef] [PubMed]

39. McMullin, D.R.; Sumarah, M.W.; Miller, J.D. Chaetoglobosins and azaphilones produced by Canadian strains of Chaetomium globosum isolated from the indoor environment. Mycotoxin Res. 2013, 29, 47-54. [CrossRef]

40. Wu, Z.J.; Li, G.Y.; Fang, D.M.; Qi, H.Y.; Ren, W.J.; Zhang, G.L. Analysis of epipolythiodioxopiperazines in fungus Chaetomium cochliodes using HPLC-ESI-MS/MS/MS. Anal. Chem. 2008, 80, 217-226. [CrossRef] [PubMed]

41. Bencsik, O.; Papp, T.; Berta, M.; Zana, A.; Forgó, P.; Dombi, G.; Andersson, M.; Salkinoja-Salonen, M.; Vágvölgyi, C.; Szekeres, A. Ophiobolin A from Bipolaris oryzae perturbs motility and membrane integrities of porcine spermandinduces cell death on mammalian somatic cell lines. Toxins 2014, 6, 2857-2871. [CrossRef]

42. Nielsen, K.F. Mold Growth on Building Materials. Secondary Metabolites, Mycotoxins and Biomarkers. Ph.D. Thesis, Technical University of Denmark, Lyngby, Denmark, 2002.

43. Rasimus, S.; Mikkola, R.; Andersson, M.; Teplova, V.; Venediktova, N.; Ek-Kommonen, C.; Salkinoja-Salonen, M. Psychotolerant Paenibacillus tundrae from barley grains produces new cereulide-like depsipeptides, paenilide, and homopaenilide, highly toxic to mammalian cells. Appl. Environ. Microbiol. 2012, 78, 3732-3743. [CrossRef] [PubMed]

44. Tonshin, A.A.; Teplova, V.V.; Andersson, M.A.; Salkinoja-Salonen, M.S. The Fusarium mycotoxins enniatins and beauvericin cause mitochondrial dysfunction by affecting the mitochondrial volume regulation, oxidative phosphorylation and ion homeostasis. Toxicology 2010, 276, 49-57. [CrossRef] [PubMed]

45. Miller, J.D.; McMullin, D.R. Fungal secondary metabolites as harmful air contaminants: 10 years on. Appl. Microbiol. Biothechnol. 2014, 98, 9953-9966. [CrossRef] [PubMed]

46. Dewangan, J.; Srivastava, S.; Mishra, S.; Pandey, P.; Aman, D.; Rath, S. Chetomin induces apoptosis in human triple-negative breast cancer cells by promoting calcium overload and mitochondrial dysfunction. Biochem. Biophys. Res. Commun. 2018, 495, 1915-1921. [CrossRef]

47. Viitanen, H.; Vinha, J.; Salminen, K.; Ojanen, T.; Peuhkuri, R.; Paajanen, L.; Lähdesmäki, K. Moisture and bio-deterioration risk of building materials and structures. J. Build. Phys. 2010, 33, 201-224. [CrossRef]

48. Vicente-Carrillo, A.; Edebert, I.; Garside, H.; Cotgreave, I.; Rigler, R.; Loitto, V.; Magnusson, K.E.; Rodríguez-Martínez, H. Boar spermatozoa successfully predict mitochondrial modes of toxicity: Implications for drug toxicity testing and the 3R principles. Toxicol. In Vitro 2015, 29, 582-591. [CrossRef]

49. Salo, J.; Andersson, M.A.; Mikkola, R.; Kredics, L.; Viljanen, M.; Salkinoja-Salonen, M. Vapor as a Carrier of Toxicity in a Health Troubled Building. In Proceedings of the Healthy Buildings 2015-Europe (ISIAQ International), Eindhoven, The Netherlands, 18-20 May 2015.

50. Mikkola, R.; Andersson, M.A.; Grigoriev, P.; Teplova, V.V.; Saris, N.-E.L.; Rainey, F.A.; Salkinoja-Salonen, M.S. Bacillus amyloliquefaciens strains isolated from moisture-damaged buildings produced surfactin and a substance toxic to mammalian cells. Arch. Microbiol. 2004, 181, 314-323. [CrossRef] [PubMed]

51. Ajao, C.; Andersson, M.A.; Teplova, V.V.; Nagy, S.; Gahmberg, C.G.; Andersson, L.C.; Hautaniemi, M.; Kakasi, B.; Roivainen, M.; Salkinoja-Salonen, M. Mitochondrial toxicity of triclosan on mammalian cells. Toxicol. Rep. 2015, 2, 624-637. [CrossRef] [PubMed]

52. An, J.; He, H.; Yao, W.; Shang, Y.; Jiang, Y.; Yu, Z. PI3K/Akt/FoxO pathway mediates glycolytic metabolism in HepG2 cells exposed to triclosan (TCS). Environ. Int. 2020, 136, 105428. [CrossRef] [PubMed]

53. Hoornstra, D.; Andersson, M.A.; Mikkola, R.; Salkinoja-Salonen, M.S. A new method for in vitro detection of microbially produced mitochondrial toxins. Toxicol. In Vitro 2003, 17, 745-751. [CrossRef] 
54. Samson, R.A.; Hoekstra, E.S.; Frisvad, J.C.; Filtenborg, O. (Eds.) Introduction to Food and Air-Borne Fungi, 6th ed.; Centraalbureau voor Schimmelcultures: Utrecht, The Netherlands, 2002.

55. Hatvani, L.; Antal, Z.; Manczinger, L.; Szekeres, A.; Druzhinina, I.S.; Kubicek, C.P.; Nagy, A.; Nagy, E.; Vágvölgyi, C.; Kredics, L. Green mold diseases of Agaricus and Pleurotus spp. are caused by related but phylogenetically different Trichoderma species. Phytopathology 2007, 4, 532-537. [CrossRef]

56. Druzhinina, I.S.; Komoń-Zelazowska, M.; Kredics, L.; Hatvani, L.; Antal, Z.; Belayneh, T.; Kubicek, C.P. Alternative reproductive strategies of Hypocrea orientalis and genetically close but clonal Trichoderma longibrachiatum, both capable of causing invasive mycoses of humans. Microbiology 2008, 11, 3447-3459. [CrossRef]

(C) 2020 by the authors. Licensee MDPI, Basel, Switzerland. This article is an open access article distributed under the terms and conditions of the Creative Commons Attribution (CC BY) license (http://creativecommons.org/licenses/by/4.0/). 